\title{
CONTRIBUCIONES AL ESTUDIO DE LA VIALLDAD INCAICA EN EL SECTOR CENTRAL DE LA QUEBRADA DE HUMAHUACA (UUJUY, ARGENTINA)
}

\author{
CONTRIBUTIONS TO THE STUDY OF INCA ROADWAYS IN THE CENTRAL \\ ZONE OF QUEBRADA DE HUMAHUACA (UUJUY, ARGENTINA)
}

PABIO OCHOAA \& Clarisa Otero ${ }^{B}$

En este trabajo se presentan los resultados de las investigaciones desarrolladas en los últimos años orientadas al estudio del Qhapaq Nan en el sector central de la Quebrada de Humahuaca (Jujuy, Argentina). A partir de la identificación de nuevos trayectos de caminos vinculados a tambos, centros administrativos, sitios estratégicos de control, campos agrícolas y un santuario de altura, se propone que el Estado Inca consolidó un nuevo sistema vial con la intención de articular espacios y controlar el tránsito. Las evidencias demuestran que este proceso pudo ser el resultado de la aplicación de políticas versátiles para anexar territorios mediante la incorporación de prácticas religiosas locales al culto estatal y la resignificación de los paisajes locales.

Palabras clave: Qhapaq Ñan, inca, control político, waka, paisaje.

This paper presents the results of research conducted in recent years on the Qhapaq Nan in the middle reaches of Quebrada de Humahuaca ravine (Jujuy, Argentina). Based on the identification of new stretches of road linked to tambos, administrative centers, strategic control points, agricultural fields and a high-altitude shrine, the authors propose that the Inca state created a new road system to connect spaces and control transit. The evidence shows that this process may have been the result of versatile policies aimed at annexing territories by incorporating local religious practices into the state religion and the resignification of local landscapes.

Keywords: Qhapaq Nan, Inca, political control, waka, landscape.

\section{INTRODUCCIÓN}

En las últimas décadas, el sistema vial incaico se ha constituido como uno de los indicadores arqueológicos más precisos para establecer los límites del Tawantinsuyu (Hyslop 1988). No solo ha sido utilizado para determinar la anexión de diversos territorios al Imperio, sino que además ha permitido avanzar sobre problemáticas relacionadas con interacción y fronteras sociales, y principalmente sobre los modos de control y organización política de las poblaciones sometidas. Quizás uno de los aportes más importantes es que se ha reconocido que el estudio integral de este sistema debe comprender tanto las características de su trazado como las de la articulación con otras estructuras próximas a la red vial. Esta asociación a sitios arqueológicos de diferente funcionalidad y los atributos propios de cada tipo de camino, desde las técnicas utilizadas para su construcción hasta las formas de emplazamiento, han servido para definir la jerarquía de los distintos tramos (Hyslop 1992) y, a su vez, evaluar la organización e integración de diversos paisajes sociales (Berenguer 2007).

A Pablo Ochoa, Instituto Interdisciplinario Tilcara, Facultad de Filosofía y Letras, Universidad de Buenos Aires, email: pabloadolfoochoa@yahoo.com.ar

B Clarisa Otero, Instituto de Ecorregiones Andinas, Universidad Nacional de Jujuy-CONICET. Instituto Interdisciplinario Tilcara, Facultad de Filosofía y Letras, Universidad de Buenos Aires, email: clarisaotero@yahoo.com.ar 
Este trabajo tiene por propósito presentar una síntesis de los principales trayectos de Camino Inca registrados hasta el momento en el sector central de la Quebrada de Humahuaca y sus quebradas tributarias. Para este sector proponemos que el emplazamiento de las distintas arterias del sistema vial respondió a un caso particular y específico de control del tránsito, como resultado de las estrategias aplicadas para organizar el territorio (Morris 1988). Estas estrategias políticas habrían incluido la instalación de tampus, centros productivos, la ampliación de campos agrícolas, enclaves estratégicos de control y la apropiación de una waka con el objetivo de resignificar el paisaje social. De allí que la red de caminos asociados a cada uno de estos sitios arqueológicos y a diferentes elementos del paisaje permite demostrar que, además de estar orientada a la conexión de distintos ambientes, sirvió para organizar espacialmente a las poblaciones locales. Por tal motivo, presentamos las características arquitectónicas y de emplazamiento de los trayectos identificados en todo este sector teniendo en cuenta su vinculación con los sitios que pudieron tener una función destacada durante la dominación inca.

\section{EL ÁREA DE ESTUDIO}

La Quebrada de Humahuaca es un corredor natural que apenas supera los $100 \mathrm{~km}$ de extensión y ofrece en cientos de kilómetros las vías de comunicación más cortas entre las yungas y la puna, y en un plano más amplio, entre el área circumpuneña y los Andes meridionales (Tarragó 2013). El Río Grande, que la atraviesa en sentido norte-sur, brinda a este valle semiárido un curso de agua permanente. A lo largo de su cauce, la quebrada presenta zonas con amplias llanuras de inundación, que superan los $3 \mathrm{~km}$ de extensión, mientras que en distintos puntos se estrecha hasta alcanzar solo $30 \mathrm{~m}$ de ancho (Reboratti 2003). Además de estos estrechos, denominados angostos, a lo largo de su cauce también se suceden desembocaduras de ríos que conforman quebradas tributarias. Estas quebradas, al igual que la troncal, han sido utilizadas desde momentos prehispánicos como corredores naturales que conectan esta región con otros ambientes (Albeck 1992).

El área específica de estudio, el sector central de la Quebrada de Humahuaca, se delimita por dos de estas quebradas tributarias. El límite norte de este sector se encuentra definido por la quebrada de Yacoraite y el sur por la quebrada de Purmamarca (fig. 1). En este trabajo también incluimos a la serranía de Tilcara ya que, además de presentar extensos campos de cultivos prehispánicos (Albeck 1993), en ella identificamos numerosos trayectos de Camino Inca utilizados para acceder de forma directa a los valles y yungas de Jujuy. En esta serranía también se cuenta con la presencia del cerro Sixilera. Proponemos que este cerro fue una waka de un importante protagonismo que funcionó como referente simbólico y espacial a nivel regional, dadas las evidencias arqueológicas encontradas en su cima y el desarrollo de peregrinaciones en el marco de festividades religiosas desde momentos prehispánicos hasta el presente. Asimismo, incluimos parte de la sierra del Mal Paso por donde ingresa el camino proveniente de la sierra del Aguilar, desde la puna, al sector central de la Quebrada de Humahuaca. En suma, en este trabajo se caracterizan los trayectos identificados en todo el sector central de la Quebrada, incluidas las quebradas tributarias, parte de la sierra del Mal Paso y la serranía de Tilcara, y se avanza en la vinculación de la red vial con distintos elementos del paisaje de carácter simbólico y con sitios arqueológicos que, en algunos casos, fueron estudiados por otros investigadores.

La metodología utilizada para cumplir con los objetivos propuestos contempló una estrategia integradora. Principalmente, se combinaron la georreferenciación de distintos indicadores del paisaje, a partir del uso de imágenes satelitales, con el desarrollo en el campo de extensas prospecciones arqueológicas, tanto en la quebrada troncal como en las tributarias para identificar tramos de red vial y sitios arqueológicos. Por otro lado, se realizó el relevamiento planialtimétrico, fotográfico y registro mediante coordenadas geográficas de distintas estructuras asociadas a los caminos. Asimismo, se tuvieron en cuenta la toponimia local, documentos históricos y antecedentes bibliográficos para la identificación de sitios y rutas. A partir del análisis de todos estos elementos se confeccionaron mapas de simulación que permitieron estimar de manera preliminar posibles vías de tránsito según la extensión y características topográficas entre distintos puntos de la Quebrada y las regiones adyacentes.

Los trayectos de camino fueron registrados a partir del uso de una ficha que incluyó variables tales como ancho, pendiente, características constructivas, sistemas de drenaje, cruces de senderos y tipos de emplazamiento (tabla 1). Vale mencionar que se puso 
Tabla 1. Características arquitectónicas y lugar de emplazamiento de los trayectos de Qhapaq Nan mencionados en el trabajo. Table 1. Architectural features and location of the Qhapaq Nan sections mentioned in this paper.

\begin{tabular}{|c|c|c|c|c|c|c|c|c|c|}
\hline \multirow{2}{*}{ TRAYECTO } & \multicolumn{4}{|c|}{ CARACTERÍSTICAS ARQUITECTÓNICAS } & \multicolumn{5}{|c|}{ LUGAR DE EMPLAZAMIENTO(PENDIENTE) } \\
\hline & $\begin{array}{c}\text { Despejado } \\
\text { o espedrado }\end{array}$ & $\begin{array}{l}\text { Con muros } \\
\text { laterales }\end{array}$ & $\begin{array}{l}\text { Con muro de } \\
\text { retención lat. }\end{array}$ & $\begin{array}{l}\text { Escalonado } \\
\text { y/o enlajado }\end{array}$ & Amojonado & Ondulada & $\begin{array}{c}\text { Rocosa } \\
\text { (zig-zag) }\end{array}$ & Natural & Lateral \\
\hline Tilcara-La Huerta & $\mathrm{x}$ & & $\mathrm{x}$ & & & & & $\mathrm{x}$ & $\mathrm{x}$ \\
\hline Yacoraite-La Huerta & $\mathrm{X}$ & $\mathrm{X}$ & $\mathrm{X}$ & & & & & $\mathrm{X}$ & $\mathrm{X}$ \\
\hline La Huerta-Sixilera & $\mathrm{X}$ & $\mathrm{X}$ & $\mathrm{X}$ & $\mathrm{X}$ & $\mathrm{X}$ & $\mathrm{X}$ & $\mathrm{X}$ & $\mathrm{X}$ & $\mathrm{X}$ \\
\hline Sixilera-Tilcara & $\mathrm{X}$ & $\mathrm{X}$ & $\mathrm{X}$ & $\mathrm{X}$ & & $\mathrm{X}$ & $\mathrm{X}$ & $\mathrm{X}$ & $\mathrm{X}$ \\
\hline La Huerta- Caspala & $\mathrm{X}$ & $\mathrm{X}$ & $\mathrm{X}$ & $\mathrm{X}$ & & $\mathrm{X}$ & $\mathrm{X}$ & $\mathrm{X}$ & $\mathrm{X}$ \\
\hline Yacoraite-El Aguilar & $\mathrm{X}$ & $\mathrm{X}$ & $\mathrm{X}$ & $\mathrm{X}$ & $\mathrm{X}$ & $\mathrm{X}$ & & $\mathrm{X}$ & $\mathrm{x}$ \\
\hline
\end{tabular}

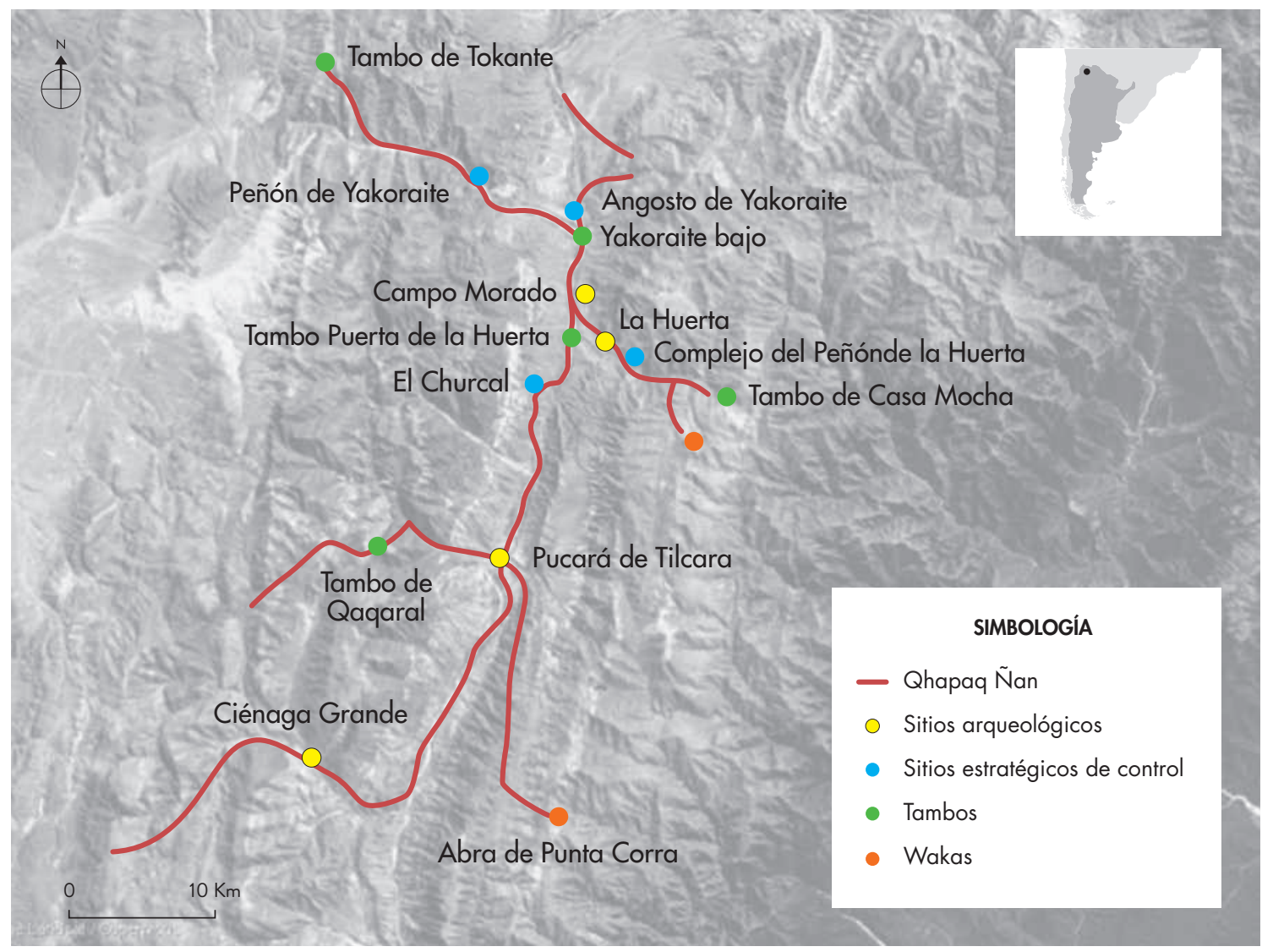

Figura 1. Mapa del sector central de la Quebrada de Humahuaca con la ubicación de los principales sitios arqueológicos que se mencionan en el texto y el trazado del Qhapaq Nan. Figure 1. Map of the central zone of the Quebrada de Humahuaca including the location of the main archaeological sites mentioned in the text, and the layout of Qhapaq Nan. 
énfasis en aquellos rasgos constructivos que permitieron asignar con precisión los senderos al Qhapaq Nan, teniendo en cuenta que posiblemente la gran mayoría de los caminos relevados fueron reutilizados desde momentos preincaicos y que pudieron constituirse incluso como caminos de herradura. Por último, las tareas de campo contemplaron la participación en las peregrinaciones al cerro Sixilera, en el marco de las celebraciones organizadas por la comunidad indígena de La Huerta. El propósito de esta participación fue el de registrar los trayectos prehispánicos que conducen al santuario de altura construido en la cima del cerro.

\section{EL QHAPAQ ÑAN EN LA QUEBRADA TRONCAL}

Los estudios sobre el Camino Inca en la Quebrada de Humahuaca se inician en la década de 1980, con los trabajos de Raffino (1983), quien propuso que una de las arterias principales del Qhapaq Nan atravesaba la quebrada en sentido norte-sur. Seguidamente, Nielsen (1989) registró tramos de camino en los sectores superiores de la serranía de Tilcara y en el sector norte de la Quebrada (Nielsen 1994; Nielsen et al. 1997). Los aportes de ambos investigadores orientaron nuestros trabajos para completar la sistematización de la red vial en el sector central de la quebrada. A los tramos relevados por Raffino (1993) próximos a La Huerta, sitio que él definiera como un centro administrativo inca, en los últimos años detectamos segmentos de camino que vinculan este sitio con el tambo Puerta de la Huerta (fig. 2a, b). Este tambo, construido a partir de la traza edilicia de un Rectángulo Perimetral Compuesto (RPC) (sensu Madrazo \& Otonello 1966), de media hectárea de superficie presenta 15 qollqas, varias terrazas de cultivo y corrales. Asimismo, sobre el faldeo del promontorio donde se emplaza, localizamos otros tramos de camino que lo conectan con el sitio arqueológico Angosto del Perchel y la posible cabecera política de la wanami de Humahuaca: el pucara de Tilcara (fig. 1) (González 1982; Williams 2004; Otero 2013). Este trayecto de dos km de extensión presenta muros de retención lateral y en algunos segmentos su ancho supera los cuatro metros (fig. 2c, d, tabla 1).

Por otro lado, sobre el espolón ubicado frente al tambo de la Huerta se registró el trazado del camino que vincula de manera paralela al Río Grande y, ha- cia el norte, el centro administrativo La Huerta con los pucaras de Campo Morado y Yacoraite (fig. 3a). Este trayecto de $6 \mathrm{~km}$ de extensión presenta variadas técnicas constructivas, como muros de retención lateral, despedrado y entre muros (fig. 3b, c, tabla 1). Asimismo, su ancho varía según las diversas formas de emplazamiento, alcanzando como máximo los cuatro metros. En trabajos anteriores fue descrito el trayecto de camino que rodea la base del pucara de Campo Morado, destacando su asociación con petroglifos posiblemente atribuibles a la época preincaica (Fernandez Do Río \& Ochoa 2010).

A los tramos identificados en torno a La Huerta, se suman otros trayectos de caminos con muros de retención lateral, próximos a dos estrechamientos naturales de la quebrada troncal, conocidos como angostos de Perchel y Yacoraite (fig. 1). En la cima de estos angostos se emplazaron poblados refuncionalizados por el Inca. A estos sitios los denominamos enclaves estratégicos de control, por presentar un difícil acceso, ofrecer un excelente dominio visual, segregar naturalmente el espacio y controlar el tránsito que fluía a lo largo de la quebrada.

El pucará de Yacoraite (Krapovickas 1981), construido sobre el angosto de Yacoraite (fig. 4a), presenta numerosas estructuras con rasgos arquitectónicos incaicos tales como nichos, muros con banqueta, ángulos rectos en las esquinas de los recintos y un RPC en la cima. Este sitio se emplaza en la desembocadura de la quebrada homónima, la cual se constituye como un corredor natural para acceder a la puna. En la base de este pucará se localizaba el tambo Yacoraite Bajo (Krapovickas 1968), lamentablemente destruido durante la construcción de la Ruta Nacional $\mathrm{N}^{\circ} 9$. Si bien Krapovickas (1968) destacó los atributos incaicos de los materiales recuperados durante sus excavaciones, actualmente es posible sostener que, efectivamente, se trató de un tambo. La lectura de fotografías aéreas tomadas antes de su destrucción permite distinguir su traza edilicia, en la que se identifica un RPC y un gran corral asociado a pequeños recintos. En su publicación, Krapovickas describe la presencia de escalones en voladizo al interior de estructuras cuadrangulares que no presentaban vanos de ingreso. De allí que se pueda estimar que se trató de qollqas. Por último, asociado a este angosto, sobre la serranía de Tilcara se encuentra el complejo prehispánico Agrícola del Moya (fig. 4b, c) (Nielsen \& Boschi 2007; Fernandez Do Río 2010), 


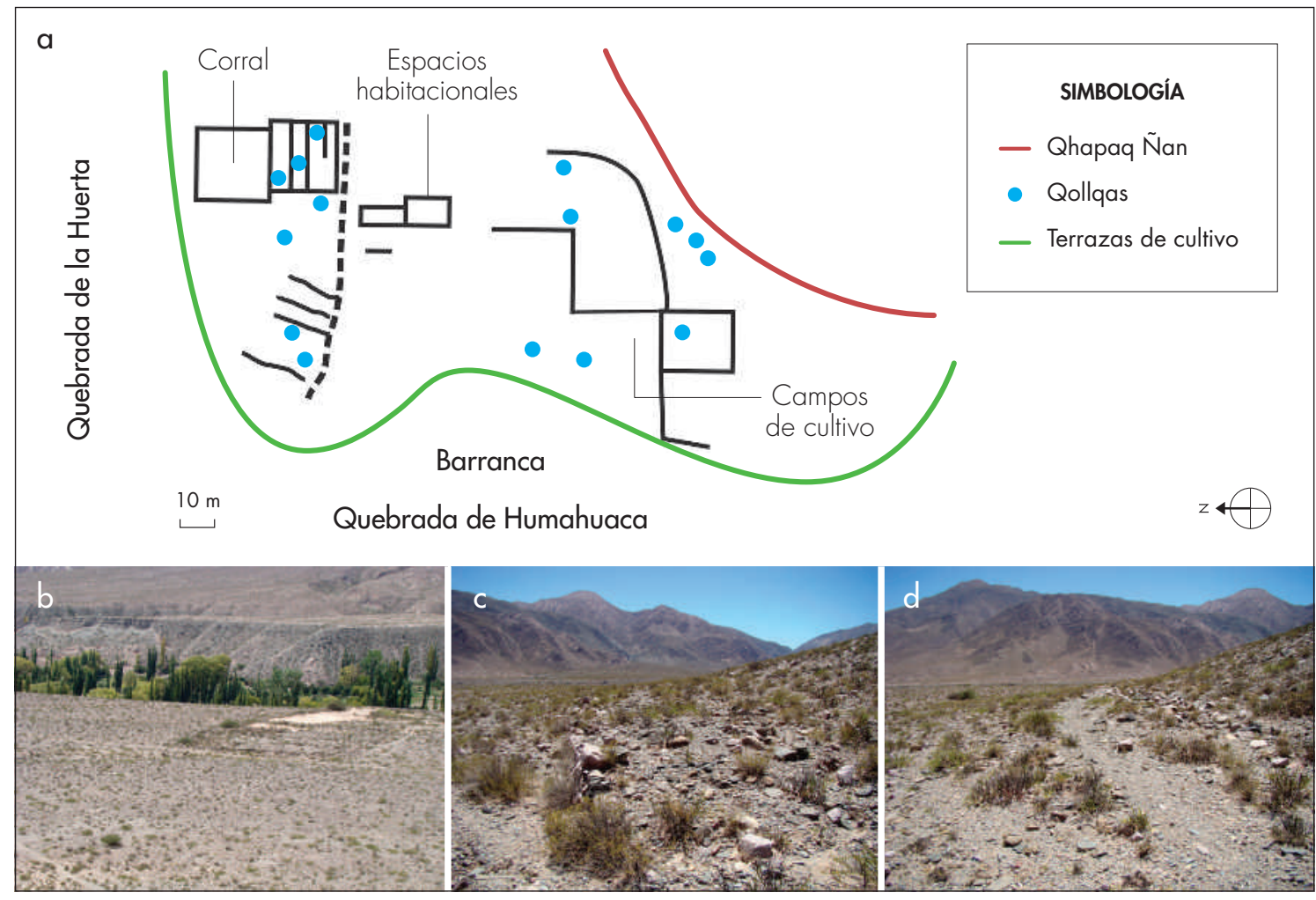

Figura 2. Tambo Puerta de la Huerta: a) planimetría; b) panorámica; c-d) tramo del Qhapaq Nan con muros de retención lateral que ingresa a La Huerta desde el sur de la Quebrada de Humahuaca. Figure 2. Tambo Puerta de la Huerta: a) planimetry; b) panoramic view; $c$-d) section of the Qhapaq Nan with lateral retaining walls, which enter La Huerta from the south along the Quebrada de Humahuaca ravine.
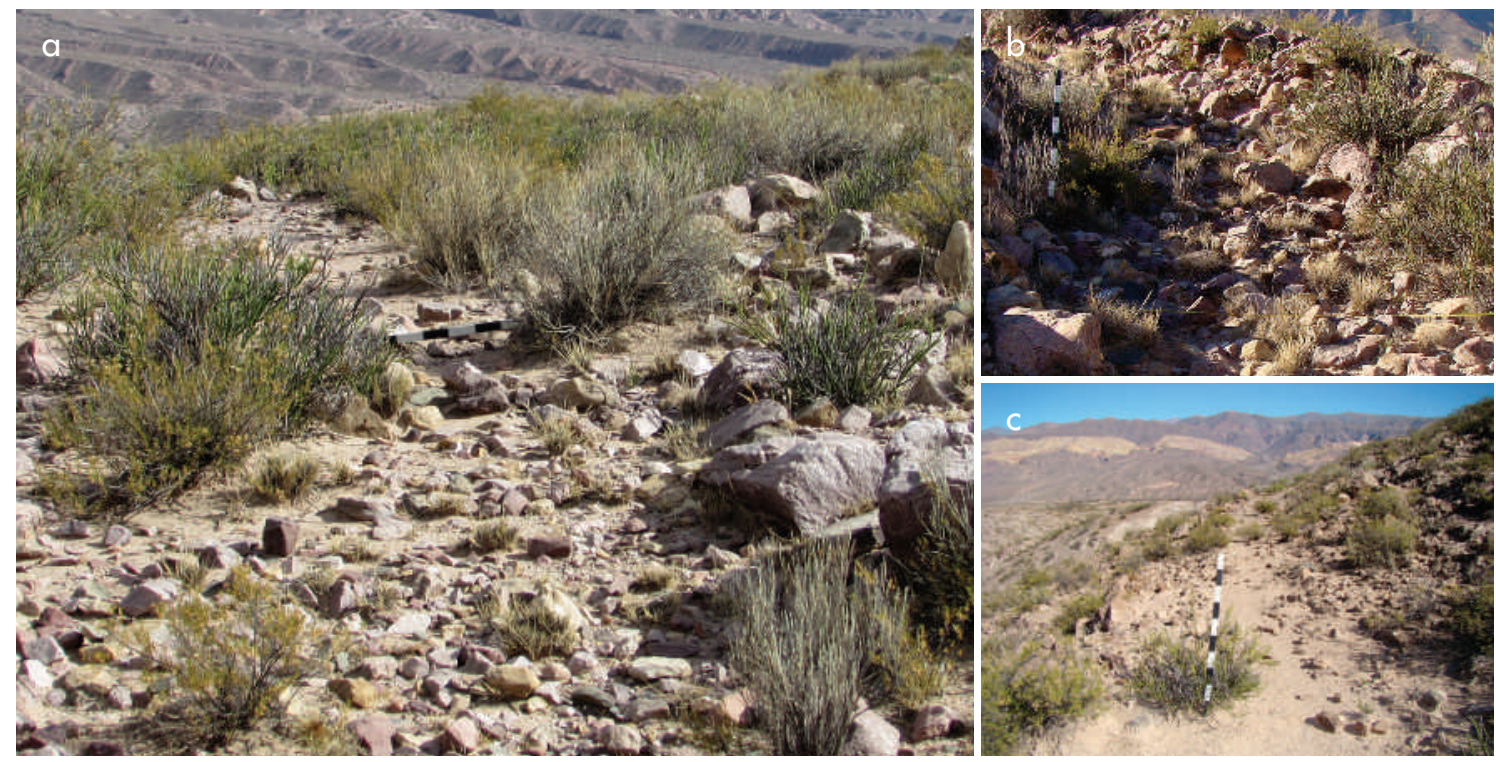

Figura 3. Tramo del Qhapaq Ñan que ingresa a La Huerta desde el norte de la Quebrada de Humahuaca: a) despedrado; b) entre muros; c) con muros de retención lateral. Figure 3. Section of the Qhapaq Ñan that enters La Huerta from the north side of the Quebrada de Humahuaca: a) cleared of stones; $\boldsymbol{b}$ ) between walls; ) with lateral retaining walls. 

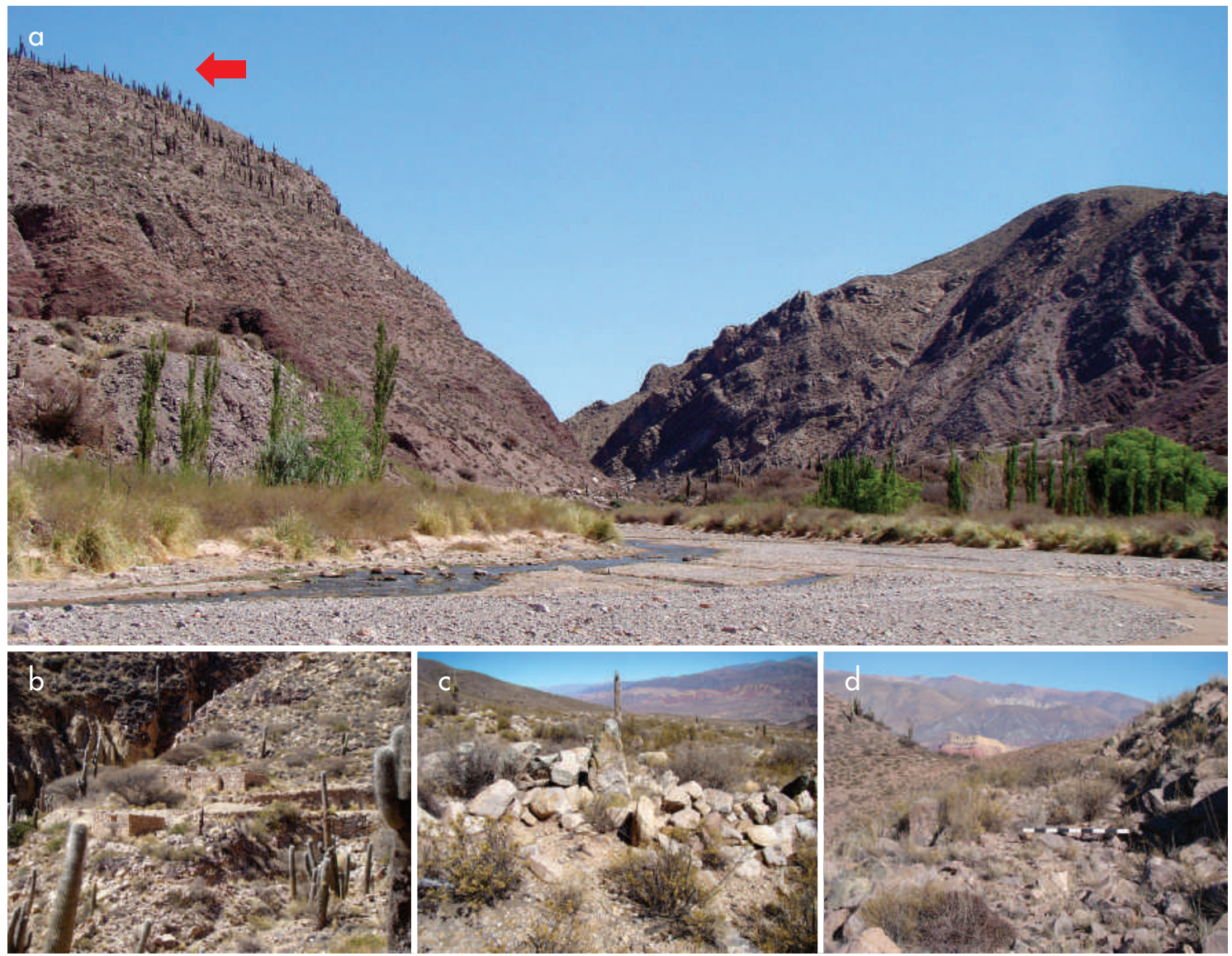

Figura 4: a) angosto de Yacoraite; b) complejo minero del Moya; c) complejo agrícola del Moya; d) tramo del Qhapaq Ñan que vinculó ambos espacios. Figure 4: $a$ ) angosto (narrows) of Yacoraite; $b$ ) Moya mining complex; c) Moya agricultural complex; $d$ ) section of $\mathrm{Qhapaq}$ Nan that connected both spaces.

donde también registramos segmentos de Camino Inca que articulan estos sitios (fig. 4d). Durante las prospecciones que realizáramos en este complejo se identificó una mina utilizada en momentos prehispánicos, asociada a pequeñas estructuras de planta lineal y cuadrangular.

A diferencia del caso de Yacoraite, el camino que atraviesa el angosto de Perchel se emplaza sobre la base del pucará de Perchel, un poblado de una hectárea de superficie ubicado a $40 \mathrm{~m}$ de altura sobre el nivel del río (fig. 5a). Este pucará cuenta con estructuras cuadrangulares, una plaza y un recinto circular. Tal como plantea Scaro (2009), si bien presenta evidencias que reflejan una ocupación preincaica, los materiales asignables al momento incaico son más abundantes. Su función principal pudo ser la de controlar el tránsito a lo largo de la Quebrada de Humahuaca. No obstante, al parecer cumplió más bien un rol de índole política y territorial. En las crónicas coloniales, este angosto es descrito como angosto de Tumi y límite norte de los tilcaras (Sánchez 2004). Otra articulación espacial refuerza la idea del carácter multifuncional que pudieron tener estos enclaves. El complejo agrícola de El Churcal (fig. 5b) (Fernandez Do Rio 2010) se encuentra en dirección al este de Perchel (fig. 1). En su conjunto, el pucara de Perchel y los caminos asociados (fig. 5c, d) debieron cumplir con un rol particular en la organización de la producción agrícola, principalmente para el desplazamiento de las personas dedicadas a las tareas campesinas y para la circulación de granos y cultivos (Albeck 1993, 2016). 

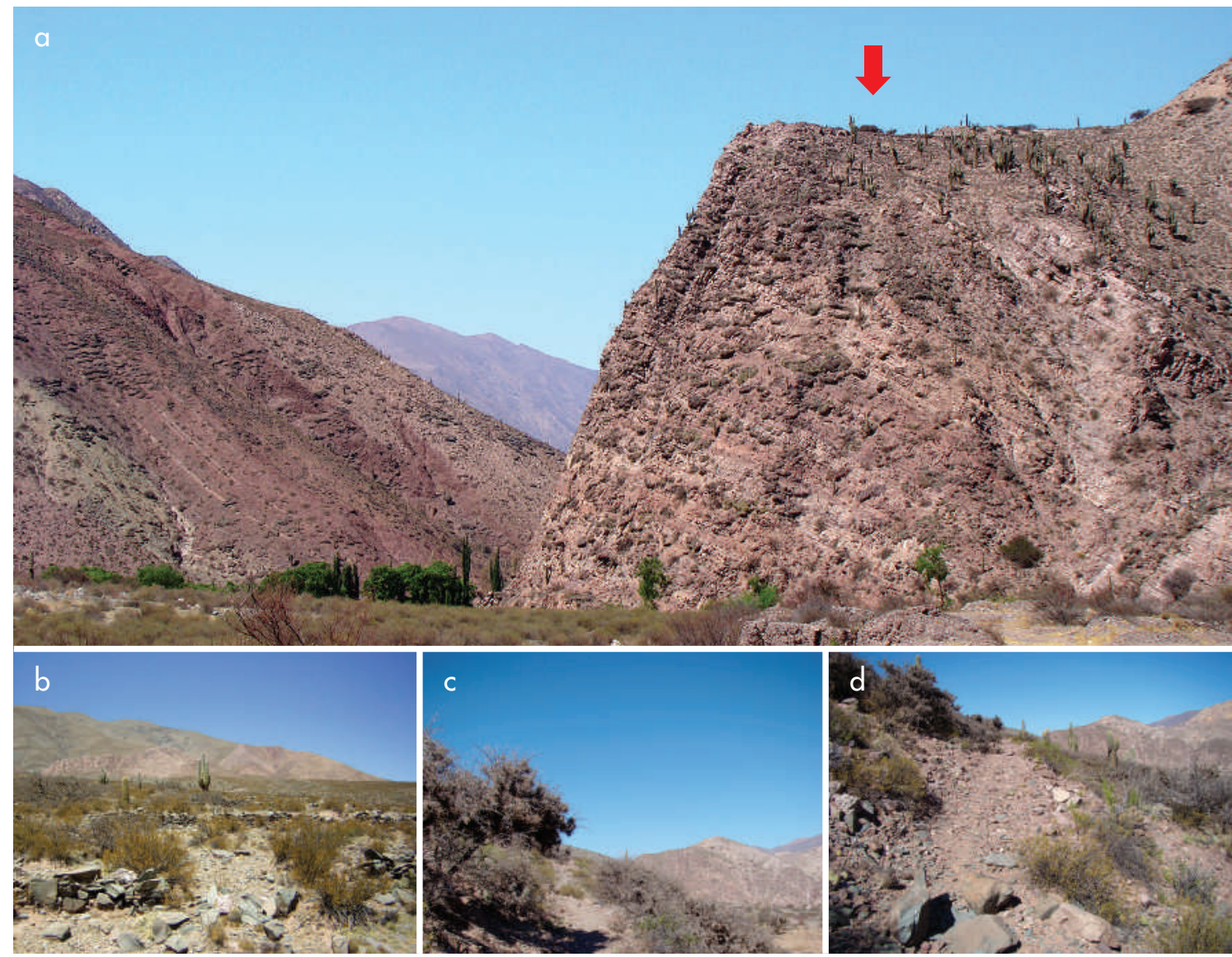

Figura 5: a) el angosto del Perchel; b) complejo agrícola del Churcal; c-d) trazado del camino que pasa por la base del sitio hacia el sur. Figure 5: $\boldsymbol{a}$ ) angosto (narrows) del Perchel; $\boldsymbol{b}$ ) Churcal agricultural complex; $\boldsymbol{c}$-d) stretch of road that passes by the base of the site, running southward.

\section{EL CAMINO INCA EN LAS QUEBRADAS TRIBUTARIAS}

\section{La quebrada de Yacoraite}

Esta quebrada fue posiblemente utilizada durante toda la historia prehispánica de la región para articular la puna con la Quebrada de Humahuaca, convirtiéndose en uno de los principales ejes de circulación en sentido este-oeste. Sobre la meseta de Los Amarillos, a la altura del cerro conocido como la Pollera de la Colla, se detectaron tramos de camino que conducían posiblemente al pucará de Yacoraite y al tambo de Yacoraite Bajo (tabla 1). Asociado a estos tramos y a $10 \mathrm{~km}$ de la desembocadura del río Yacoraite se detectó un tercer sitio estratégico de control, de características de emplazamiento en altura similares a las de los poblados identificados en los angostos (fig. 1). Este sitio, al que denominamos peñón de Yacoraite, fue construido utilizando la cuarcita rosada que aflora en la superficie de la peña (fig. 6a). Entre sus estructuras, algunas de ellas edificadas con banquetas de refuerzo, se reconocieron torreones (fig. 6b), terrazas de circulación (fig. 6c) y qollqas (fig. 6d). $\mathrm{Al}$ igual que estos rasgos arquitectónicos, el material cerámico de superficie también es asignable al momento incaico (Ochoa 2014). Este enclave estuvo posiblemente vinculado a otro tramo de camino, que fuera descrito previamente por Nielsen et al. (1997), detectado en el sector superior de la quebrada de Yacoraite y que debía articular esta quebrada con la sierra del Aguilar.

En la sierra del Aguilar identificamos un tambo y dos tramos de camino que ingresan a Casa Grande y Vizcarra desde la puna (tabla 1, fig. 1). Ambos trayectos atraviesan la sierra del Mal Paso, presentando direcciones 


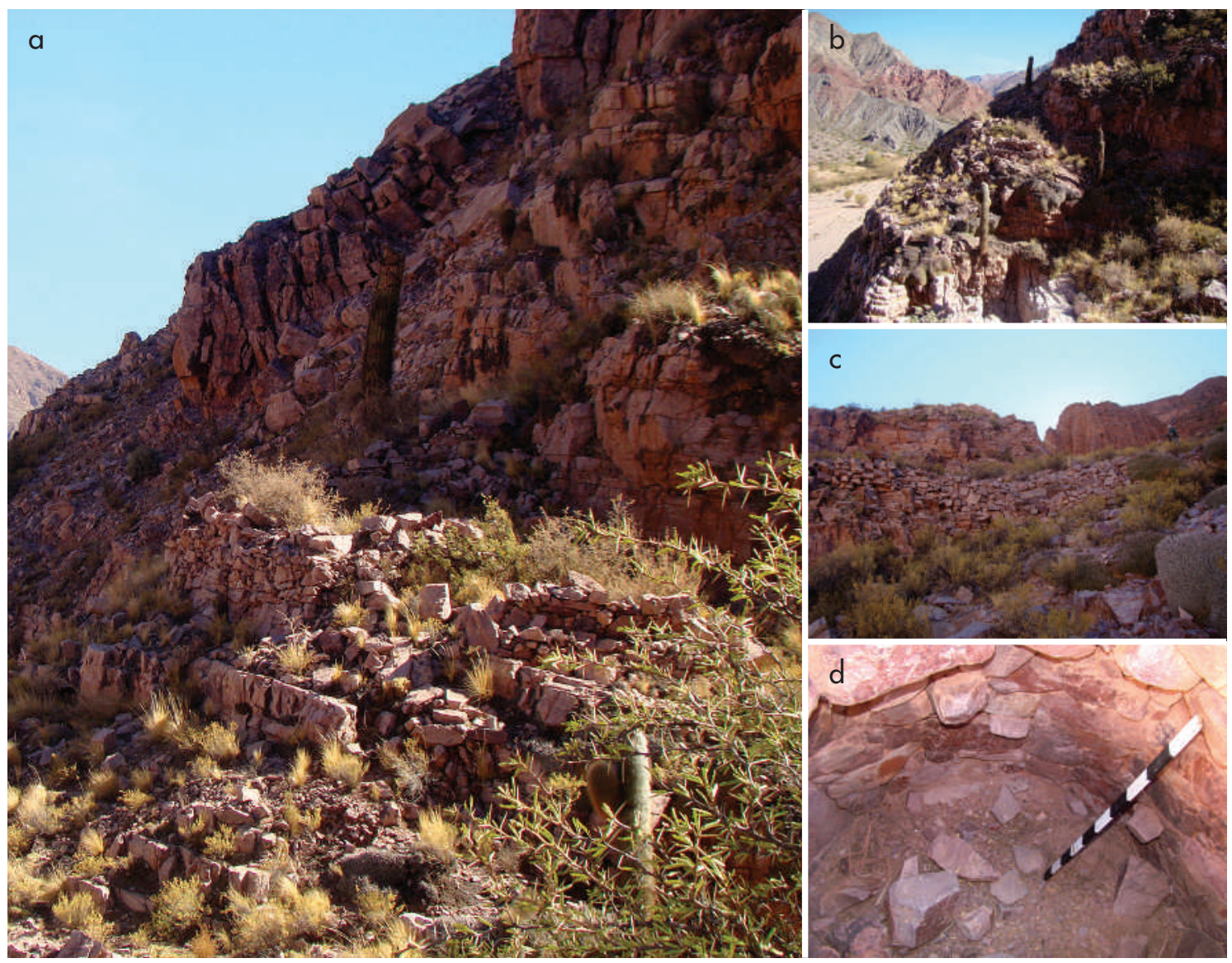

Figura 6: a-b) peñón de Yacoraite; c) extensos muros de contención; d) qollqa con escalones en voladizo. Figure 6: $\boldsymbol{a}$-b) Peñón de Yacoraite crag; $c$ ) large retaining walls; $d$ ) qollqa (storage structure) with cantilevered steps.

diferentes. Uno de ellos, posiblemente con dirección sur, articuló a esta sierra con las Salinas Grandes y con Guayatayoc. La otra vía procede del norte, desde Abralaite y Casabindo. Estos caminos se entrecruzan en la sierra del Mal Paso, de allí se bifurcan por un lado, hacia Humahuaca, y por el otro, hacia la quebrada de Yacoraite, traspasando el abra de Tokante. Esta última, a $4256 \mathrm{msnm}$, se remarca en el paisaje por una apacheta (fig. 7a), que presenta asociados numerosos materiales arqueológicos. Entre ellos se identificaron cuentas confeccionadas en rocas calcáreas y en mineral de cobre (fig. 7b), trozos de mineral de cobre nativo (fig. 7c) y fragmentos de cerámica (fig. 7d). Antes de llegar al abra, detectamos sobre un afloramiento rocoso a $4000 \mathrm{msnm}$ el tambo de Tokante (fig. 1). Este tambo presenta varias estructuras cuadrangulares, dos qollqas y un corral.

Los caminos trazados en la quebrada de Yacoraite, al igual que los detectados en la sierra del Aguilar, debieron desarrollar un papel preponderante en el acceso al sector central de la Quebrada de Humahuaca desde la puna, particularmente en el marco de las peregrinaciones al cerro Sixilera. Tal como se describe a continuación, este cerro funcionó como un importante santuario de altura, que por sus dimensiones y color es visible desde el sector medio y superior de la quebrada de Yacoraite.

\section{La quebrada de Sixilera}

Esta quebrada se constituye hasta hoy como uno de los principales corredores naturales que conducen a los valles orientales de Jujuy. A lo largo de esta arteria, consolidada mayormente como camino de herradura, se han registrado varios trayectos de Qhapaq Nan que surgen desde La Huerta y atraviesan Sixilera en dirección al Molulo (fig.s 1 y 8). En la cabecera de la quebrada de 


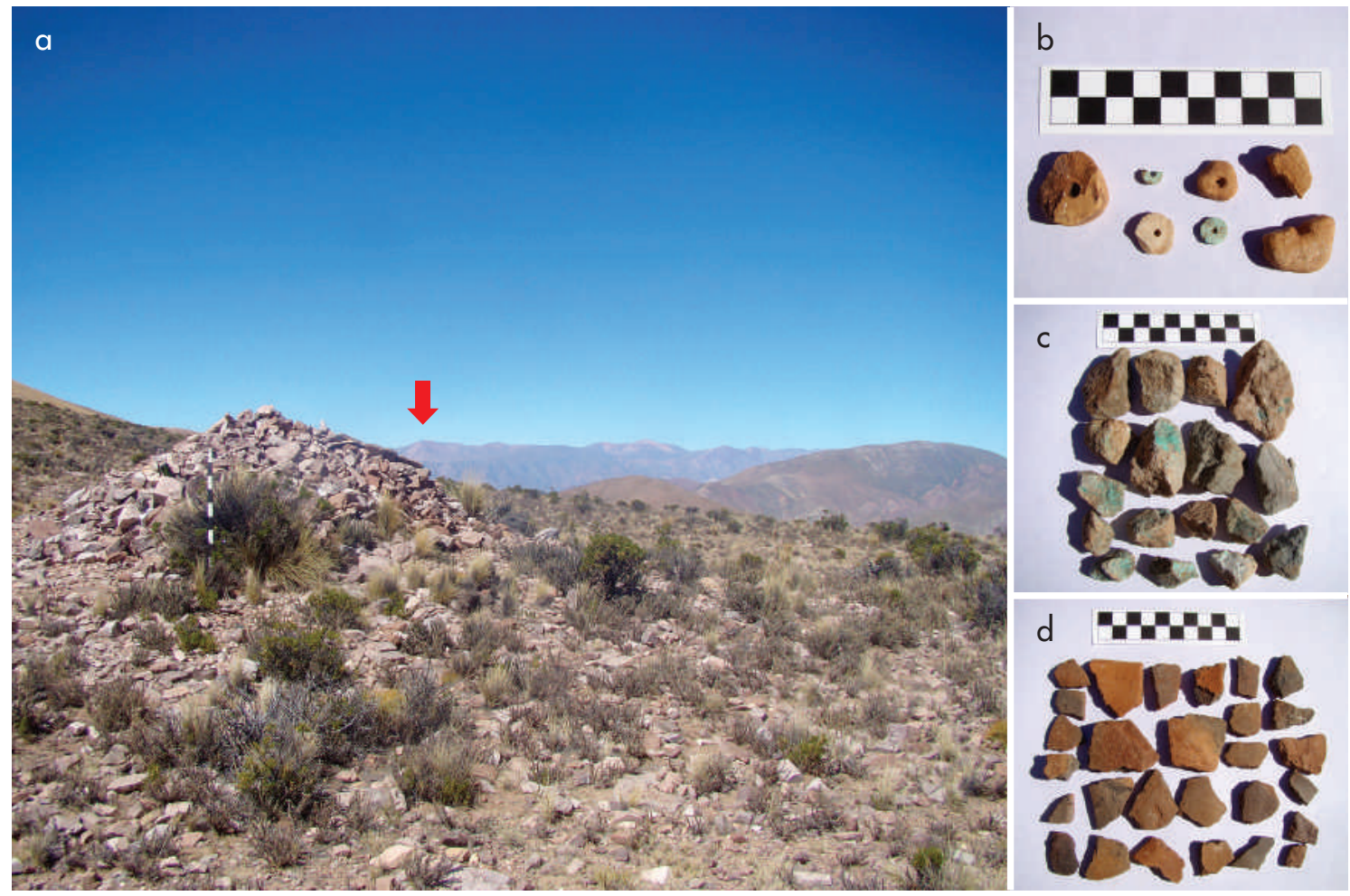

Figura 7: a) apacheta prehispánica en el abra de Tokante; b) cuentas de collar confeccionadas en roca calcárea y mineral de cobre; c) trozos de mineral de cobre; d) fragmentos de cerámica recolectados de superficie en el abra de Tokante. La flecha indica en el horizonte de la serranía de Tilcara, el cerro Sixilera. Figure 7: a) prehispanic apacheta in the abra de Tokante; $b$ ) beads made of calcareous rock and copper ore; $c$ ) pieces of copper ore; $d$ ) ceramic fragments collected from the surface in the abra de Tokante. The arrow on the horizon indicates cerro Sixilera in the Tilcara range.
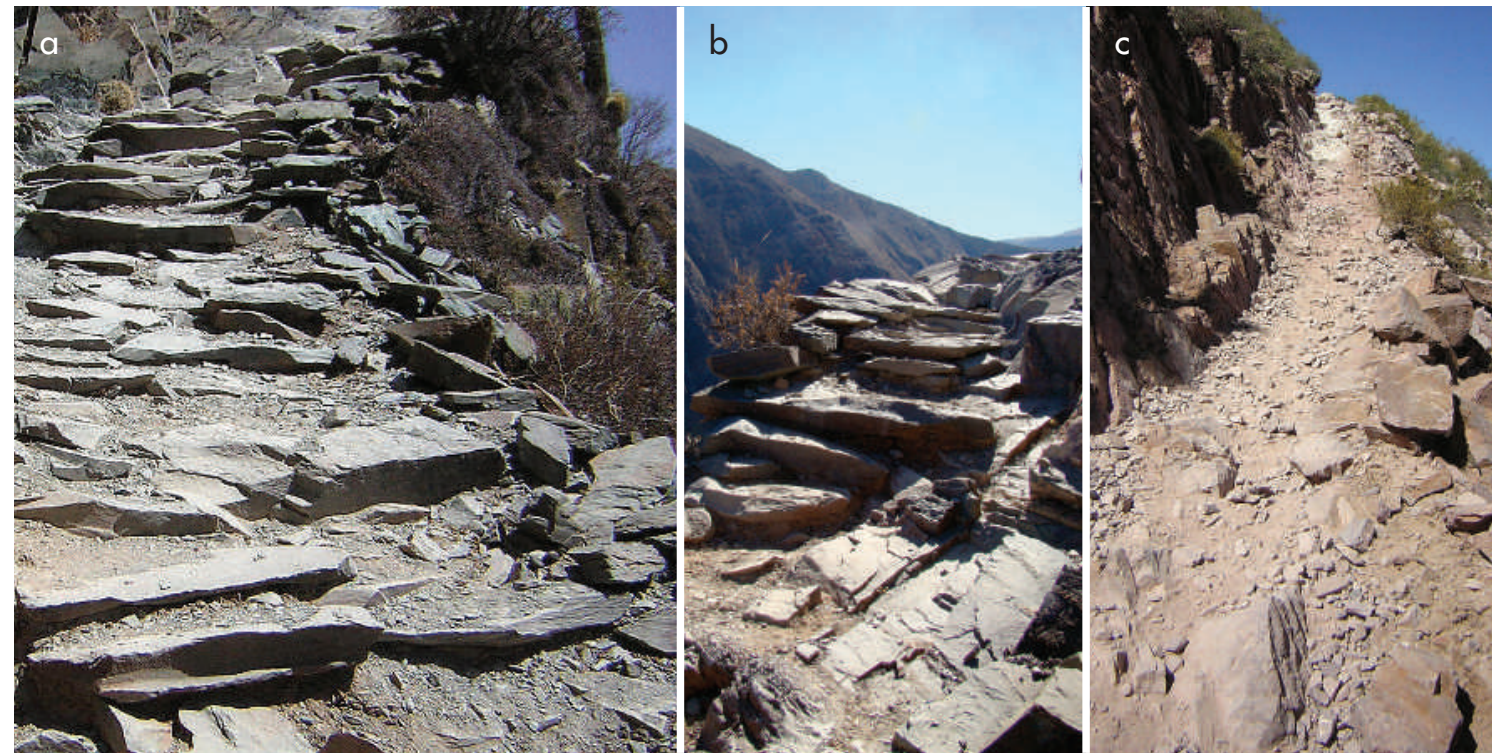

Figura 8: a-b) escalones incaicos en el camino a Sixilera; c) tramo de camino cavado sobre la roca madre en el abra del Rosado. Figure 8: $\boldsymbol{a}-\boldsymbol{b}$ ) Inca stairs in the road to Sixilera; $\boldsymbol{c}$ ) section of the road excavated in bedrock in abra del Rosado. 


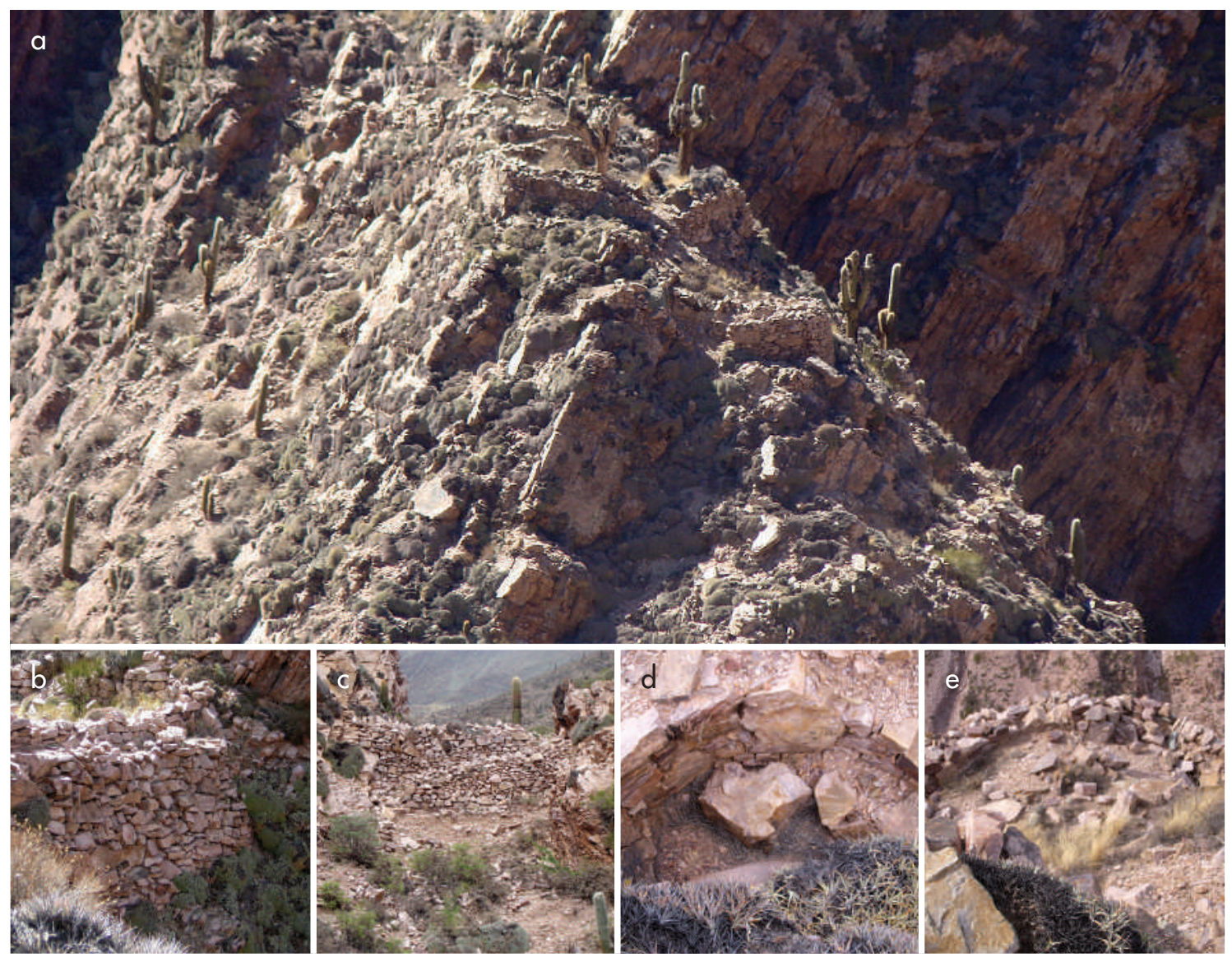

Figura 9: a) el peñón de la Huerta; b) banquetas de refuerzo; c) rampa de acceso; d-e) torreones semicirculares. Figure 9: a) peñón (crag) de la Huerta; $\boldsymbol{b}$ ) stone reinforcements; $c$ ) access ramp; $d$-e) semicircular towers.

Sixilera, en el faldeo contrario al abra del Rosado y desde donde se asciende a la serranía de Tilcara, se emplaza el complejo del peñón de la Huerta. Este complejo de sitios arqueológicos fue definido como un sistema militar vinculado al centro administrativo de La Huerta (Ochoa 2012, 2016). Los senderos registrados en esta sección de la quebrada presentan técnicas constructivas propias de la caminería inca, como el emplazamiento en zigzag, el enlajado (fig. 8a), el escalonado (fig. 8b) y el cavado sobre la roca madre (fig. 8c, tabla 1).

El complejo del peñón de la Huerta puede ser descrito también como un conjunto de sitios estratégicos de control, emplazados en altura con la intención de vigilar el tránsito hacia y procedente de las tierras bajas (fig. 9a). Entre estos sitios, ocupados durante el Período Incaico, se destacan un pucara y un enclave militar, que se caracterizan por la presencia de banquetas (fig. 9b), rampas de acceso con pisos enlajados (fig. 9c), torreones (fig. 9d, e) y terrazas de circulación (Ochoa 2012). Para su construcción, al igual que para el caso del peñón de Yacoraite, se utilizó la cuarcita rosada que aflora en la peña.

Las características arquitectónicas y el lugar de emplazamiento sugieren que el complejo del peñón de la Huerta también pudo edificarse con el propósito de controlar el acceso al cerro Sixilera (fig. 10a) (Ochoa 2016, 2017). Entre este complejo y el cerro existe un camino directo, que atraviesa la serranía de Tilcara. Este sendero, que continúa en uso, presenta escalones construidos en piedra y muros de retención lateral (tabla 1). Actualmente es transitado en el contexto de las peregrinaciones católicas bianuales que alcanzan la cima de este cerro y la capilla construida en uno de sus faldeos, con la intención de celebrar a la Virgen María bajo la advocación de Nuestra Señora del Rosario de Sixilera. El reuso masivo del espacio en torno a la capilla (fig. 10b) no permitió identificar evidencias arqueológicas, considerando la posibilidad 


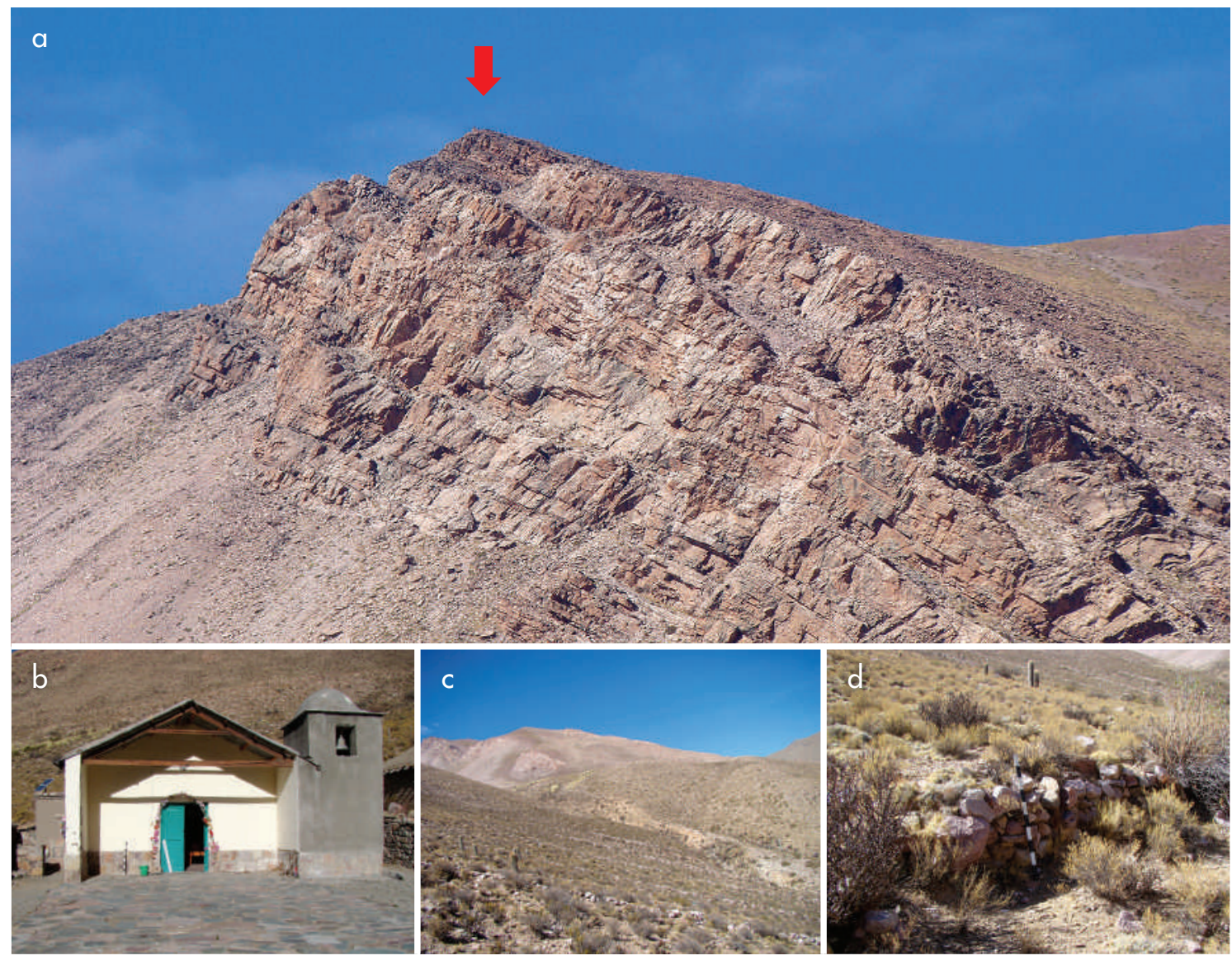

Figura 10: a) el cerro Sixilera; b) capilla de la virgen de Nuestra Señora del Rosario de Sixilera; c-d) campos de cultivo prehispánicos. Figure 10: a) Sixilera hill; $b$ ) chapel of Our Lady of the Rosary of Sixilera; $c$-d) pre-hispanic crop fields.

de que se tratara de una parada previa al ascenso hasta el oratorio ubicado a $4865 \mathrm{msnm}$, en la cúspide del cerro. No obstante, sobre los faldeos se ha identificado una gran cantidad de estructuras arqueologías dedicadas a la agricultura (fig. 10c, d). Incluso, varios tramos del camino que conecta la capilla con el oratorio de altura presentan rasgos arquitectónicos incaicos (tabla 1). Si bien el primer trayecto de ascenso se trata de un sendero entre muros, mientras que el tramo que asciende a la cima está emplazado en zigzag y consolidado con muros de retención lateral, también se destacan otras técnicas constructivas como los escalonados (fig. 11a, b, d) y enlajados (fig. 11c) (sensu Hyslop 1992). Además, se reconocieron segmentos amojonados (fig.11a), tal como describiera Guamán Poma (1980 [1615]) la colocación de piedras en los laterales de los senderos, posiblemente para actuar como marcadores espaciales del paisaje (Vitry 2002).
Durante las prospecciones efectuadas en el sector donde se encuentra el oratorio a la Virgen (fig. 12a), construido sobre la cima del cerro, se realizaron varios hallazgos arqueológicos. Entre ellos se destacan fragmentos de cerámica, puntas de proyectil de obsidiana y basalto (fig. 12b), trozos de mineral de cobre (fig. 12c) y cuentas calcáreas y de mineral de cobre (fig. 12d). Estos materiales fueron asignados a los Períodos Formativo, Medio, Tardío e Inca, demostrando así la larga perduración del culto a este cerro, considerado quizás una de las principales wakas de la región. En la cima se detectó una estructura circular, con claras características prehispánicas, y se pudo reconocer que las rocas utilizadas para edificar el gran recinto cuadrangular, que actualmente funciona como oratorio (fig. 12a), presentan un canteo regular. Es posible estimar que estas piedras hayan sido tomadas de otras estructuras arqueológicas asociadas a la circular. Si bien la profunda 


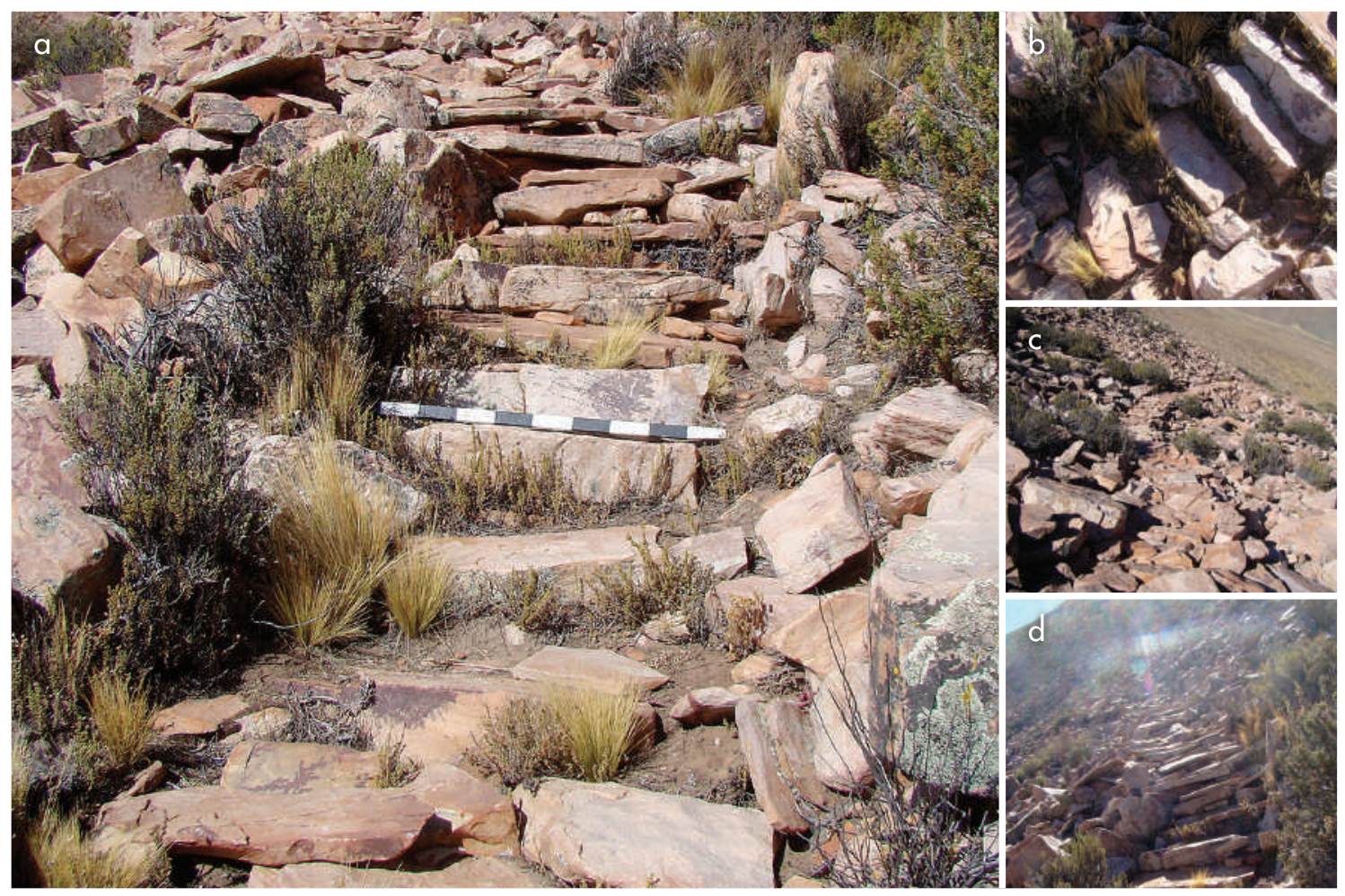

Figura 11: a) tramo de Camino Inca utilizado para ascender al santuario de altura del cerro Sixilera; b) escalonado fino; c) enlajado; d) escalonado ancho. Figure 11: a) section of the Inca Road used to ascend to the high shrine of Sixilera; $\boldsymbol{b}$ ) with stairs; $\boldsymbol{c}$ ) with flagstones; $\boldsymbol{d}$ ) wide stairs.

trayectoria de veneración a esta waka pudo implicar resignificaciones religiosas y simbólicas durante toda la época prehispánica, quizás su mayor transformación se produjo con la evangelización cristiana.

\section{La quebrada de la Cruz}

La última quebrada relevada es la de la Cruz, que debió funcionar también como uno de los corredores naturales más aprovechados para acceder a los valles y yungas. Si bien presenta una extensión limitada de tan solo $6 \mathrm{~km}$, posiblemente permitió vincular el centro administrativo de La Huerta con los sectores más elevados de la serranía de Tilcara y Zenta, en dirección al noreste (fig. 1). Desde el abra de la Cruz, ubicada a $3871 \mathrm{msnm}$, y donde Nielsen (1989) identificara previamente algunos recintos, surge una red de caminos de herradura para acceder a los caseríos de Mudana, Alonso, Yala de Monte Carmelo y a los poblados de Caspalá y Santa Ana. En todas estas localidades se encuentran distintos tipos de sitios arqueológicos, como tambos y campos agrícolas. Más allá de esta red de senderos, en los sectores inferiores de la quebrada de la Cruz y en uno de los ingresos al propio sitio arqueológico de La Huerta (fig. 13a), identificamos tramos de Camino Inca sumamente perturbados. Al parecer, dichos tramos estaban construidos a partir de la técnica de entre muros (fig. 13b, c) y con muros de retención lateral.

\section{DISCUSIÓN}

El análisis en conjunto de los distintos sitios emplazados en el sector central de la Quebrada de Humahuaca y su articulación mediante la traza del camino incaico permite plantear una organización del espacio local con fines productivos y religiosos, dentro de un escenario político que promovió el control territorial de esta subregión (Otero et al. 2017). A partir del estudio de algunas arterias del Qhapaq Ñan en asociación con sitios estratégicos para la vigilancia de los distintos corredores, proponemos que, en este sector de la Quebrada, el Estado implementó un sistema regulado de manejo de la población local según la disponibilidad de la mano 


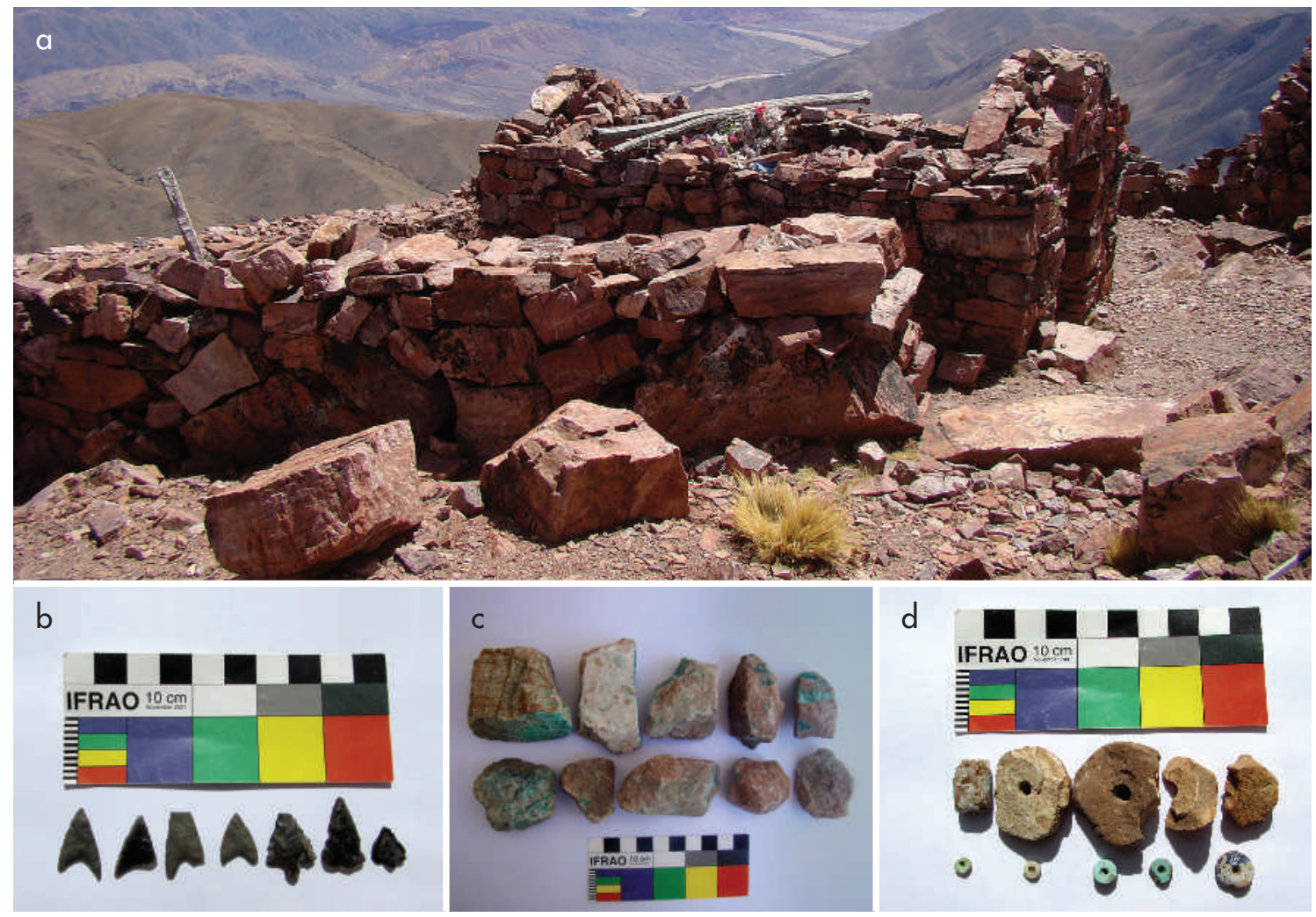

Figura 12: a) santuario de altura del cerro Sixilera; b) puntas de proyectil de obsidiana negra y basalto; c) trozos de mineral de cobre; d) cuentas de collar confeccionadas en piedra caliza, mineral de cobre, lapislázuli y valva de molusco. Figure 12: a) high shrine of Sixilera hill; b) black obsidian and basalt projectile points; $c$ ) pieces of copper ore; d) beads of limestone, copper ore, lapislazuli and mollusc valve.
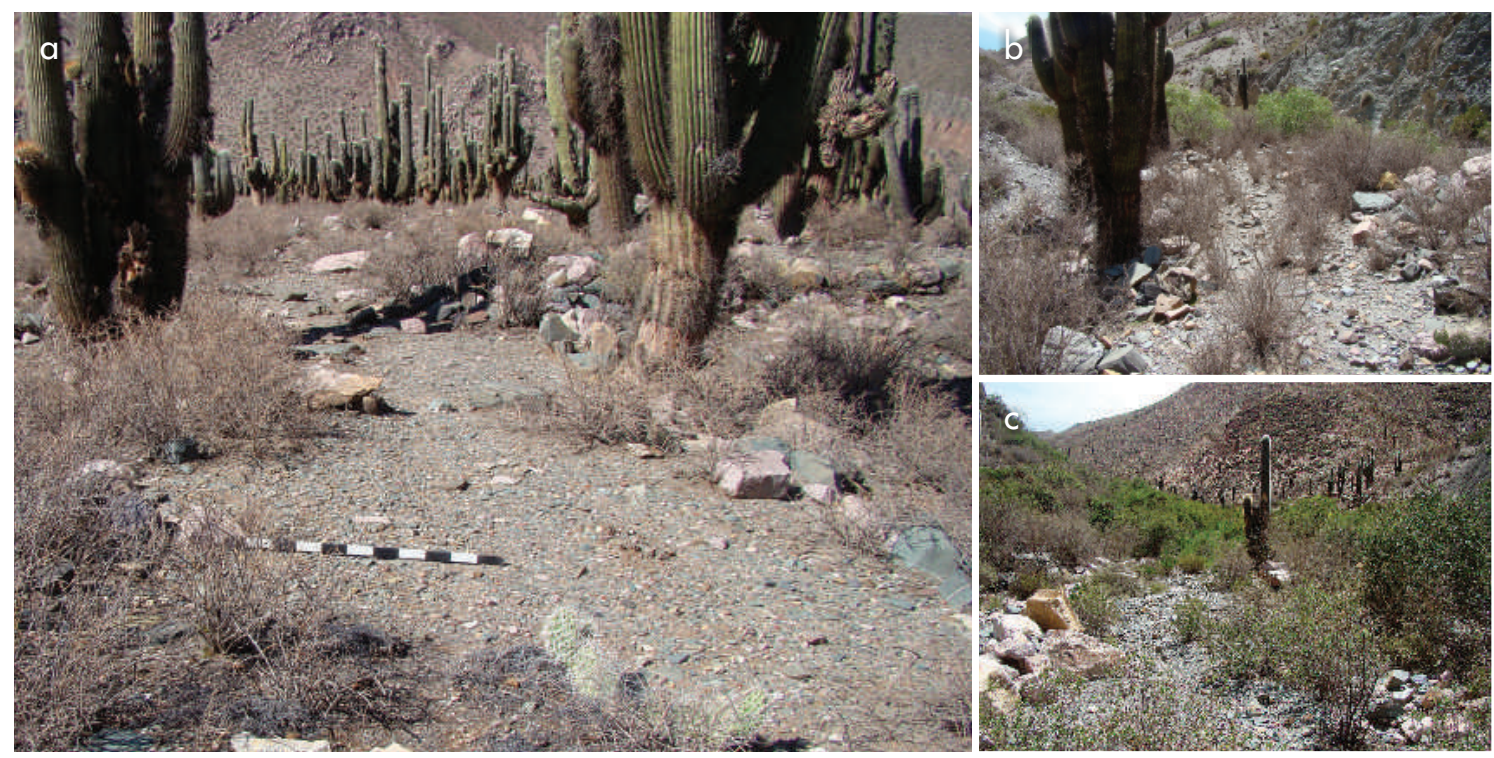

Figura 13: a) Camino Inca que sale de La Huerta hacia el abra de la Cruz; b-c) tramo de Camino Inca construido entre muros en los sectores inferiores de la quebrada de la Cruz. Figure 13: a) the Inca Road from La Huerta to abra de la Cruz; $\boldsymbol{b}$-c) section of the Inca Road running between walls in the lower ravine of quebrada de la Cruz. 
de obra y los recursos naturales. Es posible que para ejercer este tipo de control se aprovecharan las lógicas preexistentes de movilidad vinculadas al desplazamiento de estos recursos y de la gente. La aplicación de políticas versátiles fue quizás una de las estrategias administrativas más recurrentes en las provincias distantes del centro del Imperio (Santoro et al. 2010), ya que implicaba distintas instancias de negociación e imposición hasta lograr la adecuación de los intereses estatales en pos de una mayor productividad económica. En nuestro caso de estudio, el emplazamiento de sitios estratégicos de control, tambos, centros administrativos y campos agrícolas articulados entre sí, no solo a partir de la complementariedad de sus funciones, sino también por la red de caminos, indicaría que la apropiación del paisaje fue un requisito indispensable para alcanzar esta adecuación. Otro aspecto inherente a la dominación espacial pudo ser la monopolización del tránsito, tanto de la quebrada troncal como las tributarias.

En la quebrada troncal se observa un ordenamiento del espacio longitudinal, es decir, en sentido norte-sur, a través del emplazamiento de sitios de control en los angostos y de tambos en las desembocaduras de las quebradas tributarias. En ambos casos se trató de puntos de paso obligado. Este ordenamiento facilitó quizás el desarrollo de las tareas administrativas, considerando la proximidad entre estos tambos y los centros administrativos, y la corta distancia existente para acceder a los grandes campos agrícolas existentes en la serranía de Tilcara. Un ejemplo de esta articulación y organización del espacio se expresa en el emplazamiento del tambo Puerta de la Huerta ubicado a $6 \mathrm{~km}$ del centro administrativo de La Huerta, el que a su vez se encuentra a $1 \mathrm{~km}$ del complejo del peñón de la Huerta y a tan solo $4 \mathrm{~km}$ de los campos agrícolas del Churcal. Lo mismo sucede para el tambo Yacoraite Bajo, el que se encuentra espacialmente asociado al pucara de Yacoraite y al complejo agrícola minero del Moya.

Además de presentar un importante circuito longitudinal, constituido como una de las principales arterias del Qhapaq Ñan, el sector central de la Quebrada de Humahuaca se debió destacar por contar con otro importante eje de circulación, trazado a partir de la articulación entre las quebradas tributarias. Este eje transversal al Río Grande, orientado en sentido oesteeste, permitió conectar distintos ambientes, como salares y cordilleras de la puna con los valles orientales. Los principales corredores localizados en este sector debieron ser la quebrada de Yacoraite y la quebrada de la Huerta/ Sixilera. La instalación del peñón de Yacoraite y del peñón de la Huerta en los sectores inferiores de estas quebradas, próximos a sitios residenciales, demuestra la intención de controlar los puntos de paso obligado. Asimismo, resulta notoria la repetición de un patrón para instalar estos sitios, a partir del aprovechamiento de peñas que ofrecen un gran dominio visual, el uso de cuarcita rosada como materia prima para levantar las paredes de sus muros y la aplicación de técnicas constructivas similares, aunque de origen no local (Ochoa 2014).

En las quebradas tributarias el tránsito debió ser menos frecuente que en la quebrada troncal dada la distancia entre los sitios emplazados. A lo largo del eje longitudinal, la distancia entre los poblados nunca supera los $10 \mathrm{~km}$, mientras que en las tributarias puede alcanzar los $20 \mathrm{~km}$, implicando quizás jornadas de tránsito más prolongadas. A su vez, detectamos diferencias en el trazado y las técnicas constructivas de los caminos identificados en ambos tipos de quebradas (tabla 1). La caminería de la quebrada troncal presenta técnicas constructivas clásicas, como la construcción entre muros, el despedrado y el uso de muro de retención lateral (Ochoa 2014). En las quebradas tributarias, el trazado del camino que atraviesa las serranías por encima de la cota de $4000 \mathrm{msnm}$ presenta técnicas constructivas específicas, como el cavado sobre la roca madre, el enlajado, el amojonado y el escalonado (Ochoa 2014), alternadas con las técnicas clásicas. Estas diferencias respondieron quizás en mayor medida a la topografía del terreno, pero se debe tener en cuenta que también pudo tratarse de rasgos vinculados al carácter simbólico y religioso de las rutas, asociadas a abras y wakas. De allí que es pertinente reflexionar sobre la significación de algunos trayectos del Qhapaq Ñan como caminos rituales. Un ejemplo de ello pueden ser los tramos que vinculan La Huerta con el cerro Sixilera y este último con el pucara de Tilcara. Al igual que ocurre actualmente en el marco de las celebraciones católicas, estas rutas de peregrinación pudieron estar cargadas de múltiples significados a lo largo de todo su recorrido (Pimentel 2009), aportando a la constitución de un paisaje discursivo en el que el camino resulta ser su relato (Castro et al. 2004).

Como ocurrió en otros lugares de los Andes (De la Vega \& Stanish 2002; Rostworowski 2004; Platt et al. 2006), este cerro, sacralizado desde momentos prehispá- 

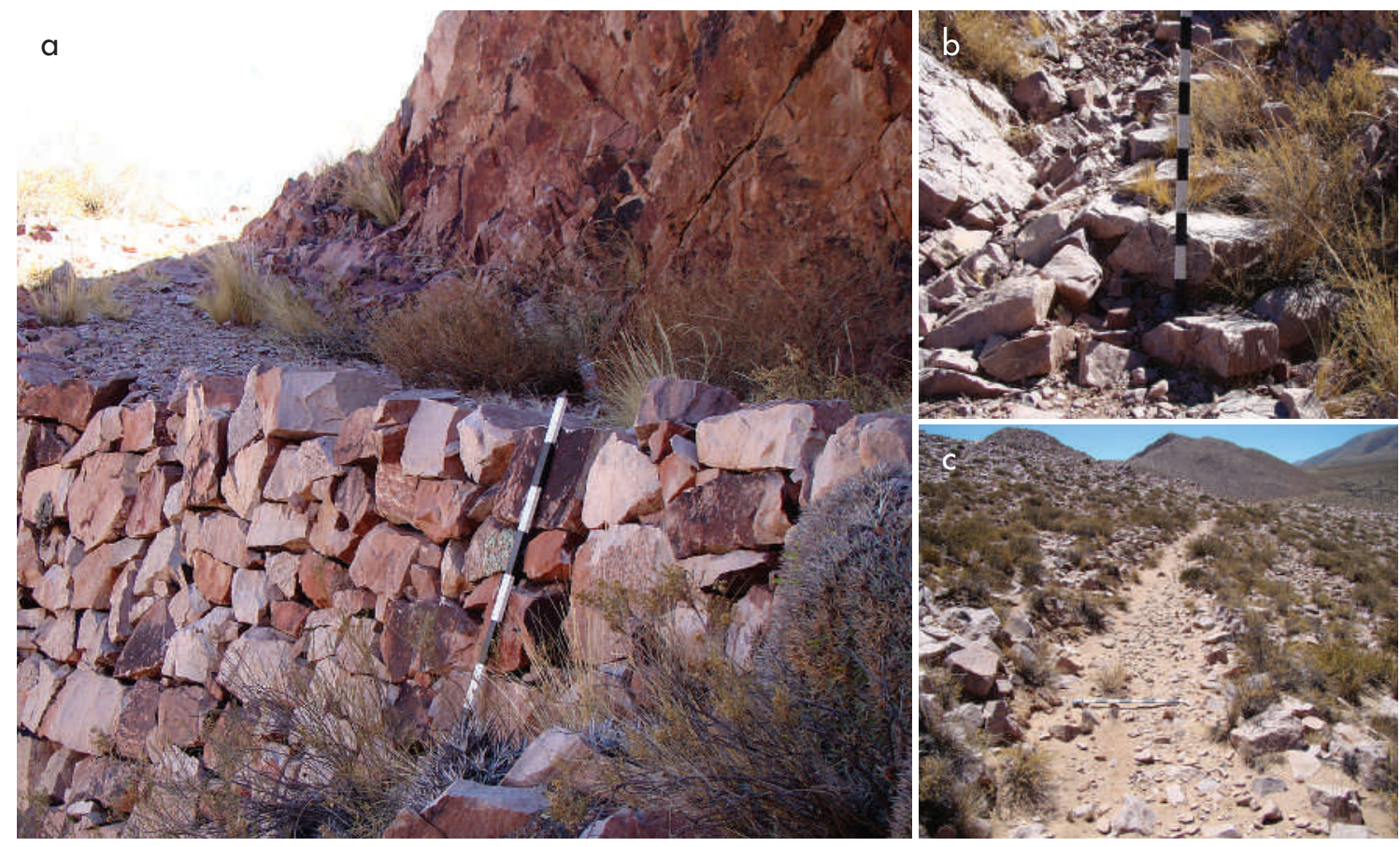

Figura 14: a) caminos de herradura que vinculan el pucara de Tilcara con el cerro Sixilera; b) escalones bien calzados en el cerro Negro; c) despedrado en Ovejería. Figure 14: a) bridlepaths connecing Pucara de Tilcara and Cerro Sixilera b) well-fitted steps at Cerro Negro; c) stone removal in Ovejería

nicos, debió resignificarse durante el régimen colonial, reemplazando así el culto de adoración a las wakas por la veneración a la Virgen María (Rostworowski 2003). No obstante, también debió resignificarse drásticamente a partir de la ocupación incaica de la quebrada. La inversión de trabajo en infraestructura vial, generada desde el Estado para ampliar y transformar la red de senderos próximos al cerro Sixilera, puede entenderse como un indicador de apropiación de un culto local para ser incorporado a la religión estatal (Ramos Gavilán 1621; Taylor 1999). A su vez, el control de los accesos a este santuario de altura debió servir para fortalecer su relevancia y jerarquía en la región, destacándolo como un centro de peregrinaje substancial para el desarrollo del Estado, tal como se hizo en otra escala para los grandes centros religiosos de impacto macrorregional (Ramos Gavilán 1621; Stanish \& Bauer 2007). Por otro lado, los caminos que articulan el cerro Sixilera con el pucara de Tilcara, caracterizado como el centro políticoadministrativo de mayor jerarquía de la región (Otero 2013, 2015), también pudieron estar embebidos de una profunda ritualidad. Estos senderos fueron acondicionados siguiendo las técnicas constructivas impuestas por el Estado. A lo largo de casi todo el trayecto presentan muros de retención lateral (fig. 14a), algunos escalones (fig. 14b) y tramos despedrados (fig. 14c) (tabla 1). Asimismo, dentro de este recorrido, el tramo de camino que desciende a Tilcara desde el Cerro Negro, tal como presentamos en trabajos anteriores (Otero \& Ochoa 2011), se encuentra asociado a estructuras que, aparentemente, estuvieron vinculadas con la observación y registro del movimiento solar.

En el paisaje ritual, el pucara de Tilcara, más allá de su rol como capital de wamani, pudo funcionar como un centro de integración regional durante las peregrinaciones desarrolladas en el marco de la adoración a esta waka para propiciar una mayor productividad económica. Este sitio cuenta con una kancha y otros espacios de congregación colectiva destinados al despliegue de parafernalia relacionada con el culto al sol, los ancestros y la fertilidad (Otero \& Ochoa 2011, 2012; Otero 2013, 2015). En estas y otras estructuras con características arquitectónicas especiales se identificaron objetos que seguramente fueron utilizados en estas festividades. Se trata de placas circulares de metal que pudieron exhibirse durante las procesiones a manera de estandartes (fig. 15a, 

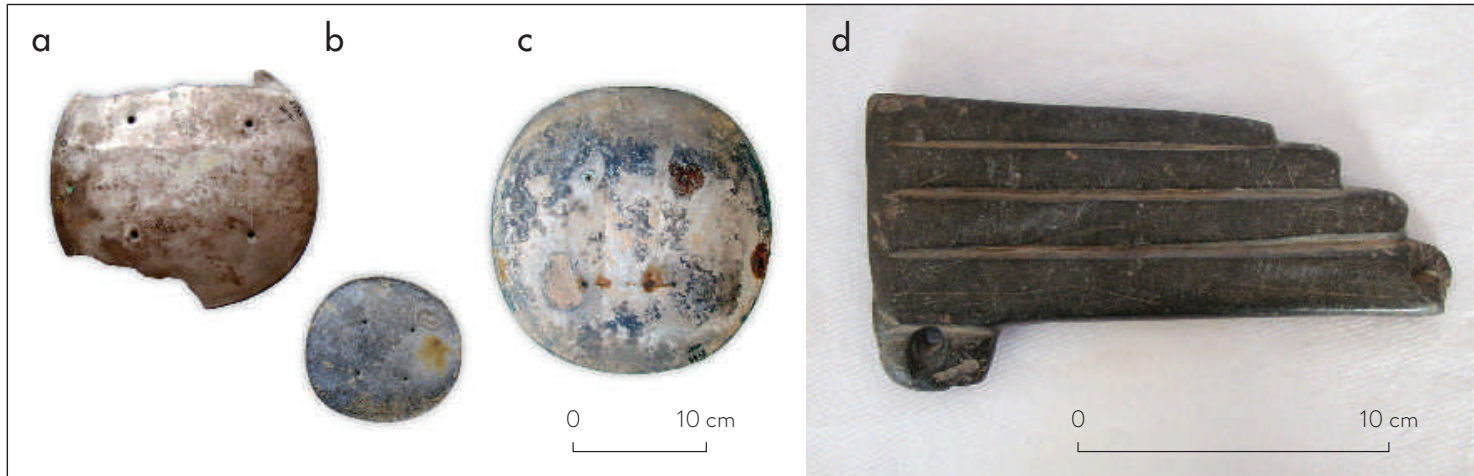

Figura 15. Discos lisos: a) Мт 2135-меJBA 6011;b) мT 3600; c) мт 2134-MEJBA 6012), sin referencias sobre su ubicación dentro del pucará; d) flauta pánica cerrada confeccionada en caliza gris (мт 2305-мЕјвA 6005). Figure 15. Smooth discs: a) MT 2135-MEJBA 6011; b) MT 3600; c) Мт 2134-МЕJBA 6012), with no information on its location inside the pucara; d) panpipe made of gray limestone (MT 2305-MEJBA 6005).

b y c) (Guamán Poma 1980 [1615]; González 1992) y numerosos instrumentos musicales, como sikuris (fig. $15 \mathrm{~d})$, trompetas y cascabeles.

Si se considera que gran parte de los caminos identificados en el sector central de la Quebrada de Humahuaca y en las quebradas de La Huerta, la Cruz y Sixilera conducen a La Huerta, queda claro que este centro administrativo debió cumplir un rol preponderante durante estas celebraciones. Al igual que el pucara de Tilcara, La Huerta debió trascender su carácter administrativo y productivo, para consolidarse como poblado multifuncional. Es uno de los pocos sitios de la Quebrada de Humahuaca que fue ampliado y remodelado casi en su totalidad por el Inca (Raffino 1993; Palma 1998, 2000). La existencia de un ancho camino que ingresa casi hasta el centro del poblado y la construcción de plazas, kallankas y de edificios con características especiales en su interior, estén reflejando tal vez una readecuación de los espacios con fines militares y religiosos, los cuales estuvieron posiblemente ligados con el culto al cerro Sixilera. Asimismo, pudo responder a la necesidad de construir grandes edificios para cumplir con los principios de reciprocidad política establecidos con las poblaciones locales (Morris 1974).

\section{CONCLUSIÓN}

A lo largo de este trabajo presentamos distintas evidencias que demuestran que el sistema vial incaico del sector central de la Quebrada de Humahuaca se materializó a través de una variada arquitectura. Esta fuerte inversión de trabajo en infraestructura vial debió implicar no solo la planificación de obras, sino también una importante intervención estatal en el área con el propósito de ordenar los espacios y controlar la circulación de personas, bienes, minerales y productos agrícolas. Es posible que esta intervención se produjera producto de las ventajas que brindaba este sector por conectar diferentes ambientes mediante cortas distancias provistas de corredores naturales. La articulación lograda a partir del tránsito entre las quebradas tributarias pudo llevar a la constitución de un nodo de interacción en el paisaje. De allí que se instalaran sitios estratégicos de control en diferentes puntos, los cuales permitieron delimitar el área y, a su vez, controlar el acceso desde los cuatro puntos cardinales. Por otro lado, el potencial productivo agrícola y minero en la región debió promover también la construcción de centros administrativos sobre poblados preexistentes $y$ la instalación de tambos con el propósito de organizar estas actividades y redistribuir los excedentes.

En este escenario, la red vial revela la conexión entre estos sitios, pero también demuestra cómo otros elementos del paisaje incidieron en la organización del espacio. Esto refiere al trazado de numerosos trayectos de Camino Inca en torno al cerro Sixilera, posiblemente una de las principales wakas de la región. Este cerro, al igual que los poblados identificados en las quebradas de Sixilera y de la Huerta, se encuentra sobre la línea del Trópico de Capricornio. La disposición de estos sitios y la waka sobre esta latitud debió proporcionar un valor simbólico extra a la región, particularmente durante las festividades del calendario ritual incaico vinculadas a los equinoccios (Bauer \& Dearborn 1998; 
Bauer 2000; Zuidema 2010). De este modo, los caminos, como marcas del paisaje, debieron ganar una mayor connotación y grado de sacralidad al ser considerados caminos rituales. La resignificación y apropiación de estos espacios por parte del Estado posibilitaron seguramente la legitimación de su poder en la región, basada en el patrocinio de celebraciones y el auspicio de creencias locales, reapropiadas tanto política como simbólicamente.

Por último, la incorporación de estas creencias al culto estatal podría manifestar dos aspectos que sumaron al desarrollo productivo y extractivo de la región. Por un lado, la aplicación de mecanismos políticos versátiles para la asimilación de grupos que pudieron desplegar diferentes estrategias de resistencia ante la dominación incaica, y por otro, el valor de la implementación de acciones propias de la esfera religiosa, a partir de la reconstrucción de la memoria colectiva local, para aglutinar poblaciones étnica y socialmente distantes en el marco de un mismo paisaje.

Reconocimientos A Joaquín Trillo por su valiosísima colaboración en los trabajos de campo. A la comunidad aborigen de La Huerta, Yacoraite y Casa Grande por permitirnos recorrer sus rutas ancestrales. A la comisión de la Virgen de Nuestra Señora del Rosario de Sixilera por permitir acercarnos y participar de sus prácticas religiosas.

\section{REFERENCIAS}

Albeck, M., 1992. El ambiente como generador de hipótesis sobre la dinámica sociocultural prehispánica en la Quebrada de Humahuaca. Cuadernos de investigación 3: 95-106.

Albeck, M., 1993. Áreas agrícolas y densidad de ocupación prehispánica en la Quebrada de Humahuaca. Avances en Arqueología 2: 56-77.

Albeck, M., 2016. Producción y lógica de la red vial en el extremo septentrional del nOA. Arqueología 22: 61-79. Buenos Aires.

BAUER, B., 2000. El espacio sagrado de los Incas. El sistema de ceques del Cuzco. Cuzco: Centro Bartolomé de las Casas.

Bauer, B. \& D. Dearborn, 1998. Astronomía e imperio en los Andes. Cuzco: Centro Bartolomé de las Casas.

Berenguer, J., 2007. El Camino Inka del Alto Loa y la creación del espacio provincial en Atacama. En Producción y circulación prehispánica de bienes en el sur andino, A. Nielsen; C. Rivolta, V. Seldes, M. Vazquez \& P. Mercolli, Eds., pp. 413-443. Córdoba: Brujas.

Castro, V.; V. Varela, C. Aldunate \& E. Araneda, 2004. Principios orientadores y metodología para el estudio del
Qhapaq Ñan en Atacama: desde el Portezuelo del Inka hasta Río Grande. Chungara 36 (2): 463-481.

Coben, L., 2006. Other Cuzcos: replicated theaters of inka power. En Archaeology and performance. Theaters of power, community, and politics, T. Inomata \& L. Coben, Eds., pp. 223-260. Oxford: Altamira Press.

De LA Vega, E. \& C. StANisch, 2002. Los centros de peregrinaje como mecanismos de integración política en sociedades complejas del altiplano del Titicaca. Boletín de Arqueología PUCP 6: 265-275. Lima.

Fernandez do Rio, S., 2010. Prácticas locales, poder imperial y control espacial. Dominio inca y relaciones coloniales en el sector medio de la Quebrada de Humahuaca. Tesis para optar al grado de Doctor en Antropología, Facultad de Filosofía y Letras, Universidad de Buenos Aires.

Fernandez do Rio, S. \& P. OchoA, 2010. El Qhapaq Nan en el sector medio de la Quebrada de Humahuaca, Jujuy. Estudios Sociales del NOA 10: 45-65. Buenos Aires.

GonZÁLEZ, A., 1982. Las provincias incas del antiguo Tucumán. Revista del Museo Nacional 46: 317-380. Lima.

GonZÁlez, A., 1992. Las placas metálicas de los Andes del sur: contribución al estudio de las religiones precolombinas. Mainz: P. Von Zabern.

Guamán Poma de Ayala, F., 1980 [1615]. Primer nueva crónica y buen gobierno, J. Murra, R. Adorno \& J. Urioste, Eds. Ciudad de México: Siglo xxi.

Hyslop, J., 1988. Las fronteras estatales extremas del Tawantinsuyu. En La frontera del Estado Inka, T. Dillehay \& P. Netherly, Eds., pp. 33-51. Oxford: BAR Internacional series 442 .

Hyslop, J., 1990. Inka settlement planning. Texas: University of Texas Press.

Hyslop, J., 1992. Qhapaqñan. El sistema vial inkaico. Lima: Instituto Andino de Estudios Arqueológicos.

Krapovickas, P., 1968. Una construcción novedosa en la Quebrada de Humahuaca (Jujuy). Etnia 7: 22-25.

KRAPOVICKAS, P., 1981. Hallazgos incaicos en Tilcara y Yacoraite (una reinterpretación). Relaciones de la Sociedad Argentina de Antropología 14 (2): 67-80.

Madrazo, G. \& M. Ottonello, 1966. Tipos de instalación prehispánica en la región de la Puna y su borde. Monografía 1. Buenos Aires: Museo Etnográfico Municipal Dámaso Arce.

Morris, C., 1974. Establecimientos estatales en el Tawantinsuyu: una estrategia de urbanismo obligado. Revista del Museo Nacional 39: 127-141. Lima.

Morris, C., 1988. Más allá de las fronteras de Chincha. En La frontera del Estado Inka, T. Dillehay \& P. Netherly, Eds., pp. 106-113. Oxford: BAR Internacional series 442.

Nielsen, A., 1989. La ocupación indígena del territorio Humahuaca oriental durante los Períodos de Desarrollos Regionales e Inka. Tesis para optar al grado de Doctor en Historia, Universidad Nacional de Córdoba.

Nielsen, A., 1995. Aportes al estudio de la producción agrícola inka en la Quebrada de Humahuaca. En Actas del XIII 
Congreso Nacional de Arqueología Chilena, Tomo I, pp. 245-256. Antofagasta.

Nielsen, A., J. Ávalos \& K. Menacho, 1997. Lejos de la ruta sin un pucara. Cuadernos 9: 203-220. Jujuy.

Nielsen, A. \& L. Boschi, 2007. Celebrando con los antepasados: arqueología del espacio público en Los Amarillos (Quebrada de Humahuaca, Jujuy, Argentina). Buenos Aires: Mallku.

OchoA, P., 2012. El peñón de la huerta. Transformación de un paisaje social, conflicto y control. Tesis para optar al grado de Licenciado en Ciencias Antropológicas. Facultad de Filosofía y Letras, Universidad de Buenos Aires.

OchoA, P., 2014. El Qhapaqñan como transformador del paisaje social en el sector central de la Quebrada de Humahuaca (Provincia de Jujuy, Argentina). En Rastros del dominio incaico en el sur andino, D. Vacaflores, Ed., pp. 51-57. Tarija: Sociedad de Etnografía e Historia de Tarija-Universidad de Bonn.

OchoA, P., 2016. Configuración del paisaje prehispánico del sector central de la Quebrada de Humahuaca (Jujuy, Argentina). Arqueoantropológicas 6 (6): 25-46.

ОсноА, P., 2017. Huacas y vírgenes: reordenamiento territorial en el sector central de la Quebrada de Humahuaca (Jujuy, Argentina). Revista Española de Antropología Americana. En prensa.

Otero, C., 2013. Producción, usos y circulación de bienes en el Pucará de Tilcara (Quebrada de Humahuaca, Jujuy). Tesis para optar al grado de Doctor en Ciencias Antropológicas. Facultad de Filosofía y Letras, Universidad de Buenos Aires.

Otero, C., 2015. Distribución y consumo de cerámica inca en el pucará de Tilcara (Quebrada de Humahuaca, Argentina). Chungara 47: 401-414.

Otero, C. \& P. OchoA, 2011. Primeras aproximaciones a la materialización del tiempo y las prácticas productivas especializadas en Tilcara (Quebrada de Humahuaca, Jujuy). Estudios Sociales del NOA, Nueva Serie 11: 101-123.

Otero, C. \& P. OсноA, 2012. Huacas, peñas y pukaras. Configuración del paisaje social en el sector medio de la Quebrada de Humahuaca (Jujuy-Argentina). En Jornadas de Estudios Andinos. Pensando la multiplicidad y la unidad en los Andes, pp. 241-243. Jujuy: Instituto Interdisciplinario Tilcara, FFYL-UBA.

Otero, C., B. Cremonte \& P. OchoA, 2017. La construcción del poder incaico en la Quebrada de Humahuaca (Jujuy, Argentina). En Interpretando huellas: arqueología, etnohistoria y etnografía de los Andes y sus tierras bajas, M. Muñoz \& M. Còmbes, Eds. Cochabamba: Universidad Mayor de San Simón-Instituto de Investigaciones Antropológicas y Museo Arqueológico-IfEA-Agencia Sueca de Desarrollo Internacional AsDi. En prensa.

Palma, J., 1998. Curacas y señores: una visión de la sociedad política prehispánica en la Quebrada de Humahuaca. Tilcara: Instituto Interdisciplinario de Tilcara, Facultad de Filosofía y Letras, Universidad de Buenos Aires.
Palma, J., 2000. Urbanismo y complejidad social en la región Humahuaca. Estudios Sociales del NOA 3: 31-57.

Pimentel, G., 2009. Las huacas del tráfico. Arquitectura ceremonial en rutas prehispánicas del Desierto de Atacama. Boletín del Museo Chileno de Arte Precolombino 14 (2): 9-38.

Platt, T., T. Bouysse-Cassagne \& O. Harris, 2006. Qaraqara-Charka. Mallku, Inka y Rey en la provincia de Charcas (siglos XV-XVII). Historia antropológica de una confederación aymara. La Paz: Instituto Francés de Estudios Andinos-Fundación Cultural del Banco Central de Bolivia-University of St. Andrews-Plural.

RAffino, R., 1983. Los Inkas del Kollasuyu. La Plata: Ramos Americana.

Raffino, R., 1993. Inka. Arqueología, historia y urbanismo del altiplano andino. Buenos Aires: Corregidor Ediciones.

Ramos Gavilán, A., 1621. Historia del célebre santuario de Nuestra Señora de Copacabana y sus milagros e invención de la Cruz de Carabuco. La Paz: Archivo y Biblioteca Nacionales de Bolivia.

Reboratti, C., 2003. La quebrada. Geografía, historia y ecología de la Quebrada de Humahuaca. Buenos Aires: La Colmena.

Rostworowski, M., 1988. Historia del Tahuantinsuyu. Lima: Instituto de Estudios Peruanos.

Rostworowski, M., 2000. Estructuras andinas del poder: ideología religiosa y política. Lima: Instituto de Estudios Peruanos.

Rostworowski, M., 2003. Peregrinaciones y procesiones rituales en los Andes. Journal de la siciété des américanistes 89 (2): 97-123.

Rostworowski, M., 2004. La influencia wari en el incario y las peregrinaciones. Boletín de Arqueología PUCP 8: 23-30.

SAlas, A., 1945. El antigal de Ciénaga Grande (Quebrada de Purmamarca, Provincia de Jujuy). Buenos Aires: Museo Etnográfico FFYL-UBA.

SÁnCHEZ, S., 2004. Discursos y alteridades en la Quebrada de Humahuaca (Provincia de Jujuy, Argentina): identidad, parentesco, territorio y memoria. Boletín de Arqueología PUCP 8: 111-132.

Santoro, C.; V. Williams, D. Valenzuela, A. Romero \& V. STANDEN, 2010. An archaeological perspective on the Inka provincial administration of the south-central Andes. En Distant provinces of the Inka Empire. Toward a deeper understanding of Inka imperialism, M. Malpass \& S. Alconini, Eds., pp. 44-74. Iowa: Universidad de Iowa Press.

ScAro, A., 2009. El Pukara de Perchel (Til 4): arqueología e historia de un lugar estratégico en la Quebrada de $\mathrm{Hu}$ mahuaca (Jujuy, Argentina). Tesis para optar al grado de Licenciado en Antropología, Facultad de Humanidades y Ciencias Sociales, Universidad Nacional de Jujuy.

Stanisch, C. \& B. Bauer, 2007. Pilgrimage and the geography of power in the Inka Empire. En Variations in the expression of Inka power, J. Pillsbury \& J. Quilter, Eds., pp. 45-83. Washington, D.C.: Dumbarton Oaks Research Library and Collection. 
TAYlor, G., 1999. Ritos y tradiciones de Huarochiri del siglo XVII. Lima: Instituto Francés de estudios andinos.

TARragó, M., 2013. Reflexiones sobre la arqueología del Noroeste Argentino en el ámbito de los Andes circumpuneños. En Las tierras altas del área centro sur andina entre el 1000 y el 1600 D.C. TANOA II, pp. 23-42. Jujuy: Ediunju.

VItrY, C., 2002. Apachetas y mojones, marcadores espaciales del paisaje prehispánico. Revista Escuela de Historia 1 (1): 179-191.
Williams, V., 2004. Poder estatal y cultura material en el Kollasuyu. Boletín de Arqueologia PUCP 8: 209-245.

Zuidema, T., 2010. El calendario inca. Tiempo y espacio en la organización ritual del Cuzco. La idea del pasado. Lima: Fondo Editorial del Congreso del Perú-Fondo editorial del PUCP. 